\title{
Review
}

\section{Protein tyrosine phosphatases as potential therapeutic targets}

\author{
Rong-jun HE* , Zhi-hong YU, Ruo-yu ZHANG, Zhong-yin ZHANG* \\ Department of Biochemistry and Molecular Biology, Indiana University School of Medicine, 635 Barnhill Drive, Indianapolis, IN 46202, \\ USA
}

\begin{abstract}
Protein tyrosine phosphorylation is a key regulatory process in virtually all aspects of cellular functions. Dysregulation of protein tyrosine phosphorylation is a major cause of human diseases, such as cancers, diabetes, autoimmune disorders, and neurological diseases. Indeed, protein tyrosine phosphorylation-mediated signaling events offer ample therapeutic targets, and drug discovery efforts to date have brought over two dozen kinase inhibitors to the clinic. Accordingly, protein tyrosine phosphatases (PTPs) are considered next-generation drug targets. For instance, PTP1B is a well-known targets of type 2 diabetes and obesity, and recent studies indicate that it is also a promising target for breast cancer. SHP2 is a bona-fide oncoprotein, mutations of which cause juvenile myelomonocytic leukemia, acute myeloid leukemia, and solid tumors. In addition, LYP is strongly associated with type 1 diabetes and many other autoimmune diseases. This review summarizes recent findings on several highly recognized PTP family drug targets, including PTP1B, Src homology phosphotyrosyl phosphatase 2 (SHP2), lymphoid-specific tyrosine phosphatase (LYP), CD45, Fas associated phosphatase-1 (FAP-1), striatal enriched tyrosine phosphatases (STEP), mitogen-activated protein kinase/dual-specificity phosphatase 1 (MKP-1), phosphatases of regenerating liver-1 (PRL), low molecular weight PTPs (LMWPTP), and CDC25. Given that there are over 100 family members, we hope this review will serve as a road map for innovative drug discovery targeting PTPs.
\end{abstract}

Keywords: drug target; protein tyrosine phosphatases; PTP1B; Src homology phosphotyrosyl phosphatase 2; lymphoid-specific tyrosine phosphatase; Fas associated phosphatase-1; CD45 antigen; striatal enriched tyrosine phosphatases; mitogen-activated protein kinase phosphatases; phosphatases of regenerating liver-1; low molecular weight PTPs; CDC25

Acta Pharmacologica Sinica (2014) 35: 1227-1246; doi: 10.1038/aps.2014.80; published online 15 Sep 2014

\section{Introduction}

Target-based drug discovery has become the dominant strategy in the pharmaceutical industry ${ }^{[1]}$. It focuses on a diseaseassociated target with the goal of developing molecules modulating target activity to provide potential therapeutics for disease treatment. In this process, target identification and validation play a pivotal role in the drug discovery project's success. The number of known drug targets is approximately 300 for all approved therapeutic drugs, in which a large portion of them belongs to ion channels, G protein coupled receptors, and protein kinases ${ }^{[2]}$. Protein tyrosine kinases (PTKs) are a very important class of oncology drug targets with $>20$ small molecule kinase inhibitors already FDA-approved for various cancer treatments, and a large number of kinase inhibitors are currently under various stages of clinic trials ${ }^{[3]}$.

\footnotetext{
\# The first two authors contributed equally to this work.

${ }^{*}$ To whom correspondence should be addressed.

E-mail zyzhang@iu.edu

Received 2014-05-29 Accepted 2014-07-31
}

PTKs and protein tyrosine phosphatases (PTPs) reversibly and coordinately control cellular protein tyrosine phosphorylation levels, which are important for nearly all cellular processes, such as growth, differentiation, migration, survival, and apoptosis $^{[4]}$.

In Chinese philosophy, the concept of Yin-Yang is used to describe the importance of balance between two seemingly opposite or contrary forces in the natural world ${ }^{[5]}$, and protein tyrosine phosphorylation and dephosphorylation represent exactly such a Yin-Yang relationship. At the molecular level, the extent of tyrosine phosphorylation is precisely balanced by the actions of specific PTK(s) and PTP(s), which can either upor downregulate downstream signaling pathways, depending on whether the phosphorylation activates or inhibits protein function $^{[4]}$. Aberrant tyrosine phosphorylation resulting from the perturbed PTK-PTP balance can cause numerous human diseases. Indeed, excessive tyrosine phosphorylation is a hallmark of cancer. Given the great success of drug discovery targeting against PTKs and the fact that proper cellular tyrosine phosphorylation levels are controlled by the coordinated 
activity of kinases and phosphatases, PTPs have been suggested as next generation drug targets ${ }^{[6-8]}$. PTPs have been important topics of research in biomedical science for the past two decades, and a number of PTPs have been implicated in various human diseases, such as cancer, diabetes, autoimmune, and neurological diseases ${ }^{[9-11]}$. These findings have further strengthened the belief that targeting PTPs could be the next frontier in drug discovery.

The PTPs constitute a large family of enzymes with 107 members divided into 4 groups based on their protein sequences and functions (Figure 1$)^{[8,12]}$. The major group is class I PTPs, which includes 99 members, and each member shares a conserved active site sequence $(\mathrm{H} / \mathrm{V}) \mathrm{C}(\mathrm{X})_{5} \mathrm{R}(\mathrm{S} / \mathrm{T})$ with the cysteine as the catalytic residue in the dephosphorylation reaction. Class I is further divided into classic tyrosinespecific PTPs, and tyrosine and serine/threonine dual-specific phosphatases (DUSP), with 38 and 61 members, respectively. Classical tyrosine-specific PTPs are composed of 17 cytosolic PTPs and 21 trans-membrane receptor-like PTPs, and the DUSPs are further divided into MKP, Myotubularin, CDC14, Slingshot, PTEN, PRL, and atypical DSP subclasses. Class II PTP has only one member, the low molecular weight (LMW) PTP, and class III has three members, namely CDC25A, CDC25B, and CDC25C. Class II and class III PTPs also have catalytic cysteine residues. Class IV PTPs have 4 members with catalytic aspartic acid residues, which is in contrast to Class I, II, and III PTPs. Class IV PTPs activities also require the presence of a metal ion, suggesting they have unique evolution origins ${ }^{[13]}$.

Given the large number of PTPs, a summary of potential drug targets is highly important and will serve as a road map for drug discovery efforts targeting PTPs. Although reviews on similar topics are available ${ }^{[7,14]}$, they were published more than ten years ago, during which significant research advances have been made. Thus, this perspective aims to provide an updated view on this subject and a summary of recent research findings. We will cover well recognized and validated PTP targets in the field, including PTP1B, SHP2, LYP, CD45, FAP-1, STEP, MKP-1, PRL, LMWPTP, CDC25 (Figure $2)$, with a focus on their implications in human diseases.

\section{PTP1B in diabetes and cancer}

PTP1B, encoded by the PTPN1 gene, is a ubiquitously expressed classical non-receptor PTP with 435 amino acids ${ }^{[15]}$. It has an $\mathrm{N}$-terminal catalytic domain, two proline-rich sequences, and a C-terminal hydrophobic region (Figure 2). Biochemical and genetic studies have indicated that PTP1B is a key negative regulator of insulin and leptin signaling pathways (Figure 3A), which are important regulators of body weight, glucose homeostasis, and energy expenditure ${ }^{[16]}$. PTP1B downregulates insulin signaling by directly dephosphorylating insulin receptor (IR) and insulin receptor substrates (IRS) ${ }^{[17,18]}$, while it regulates leptin signaling by dephosphorylating activated JAK2 and STAT3 ${ }^{[19,20]}$. PTP1B antibodies and small molecule inhibitors have been shown to increase insulin-stimulated IR, IRS and STAT3 phosphorylation ${ }^{[21,22]}$, suggesting that PTP1B inhibition could sensitize insulin and leptin signaling pathways. Importantly, PTPN1-deficient mice exhibit enhanced insulin sensitivity and leptin hypersensitivity and have lower blood glucose and basal insulin levels. These mice were also more resistant to high-fat diet-induced weight gain ${ }^{[23,24]}$.

Decreased insulin sensitivity is a hallmark of type 2 diabetes, which accounts for $90 \%$ of diabetes cases. In this regard,

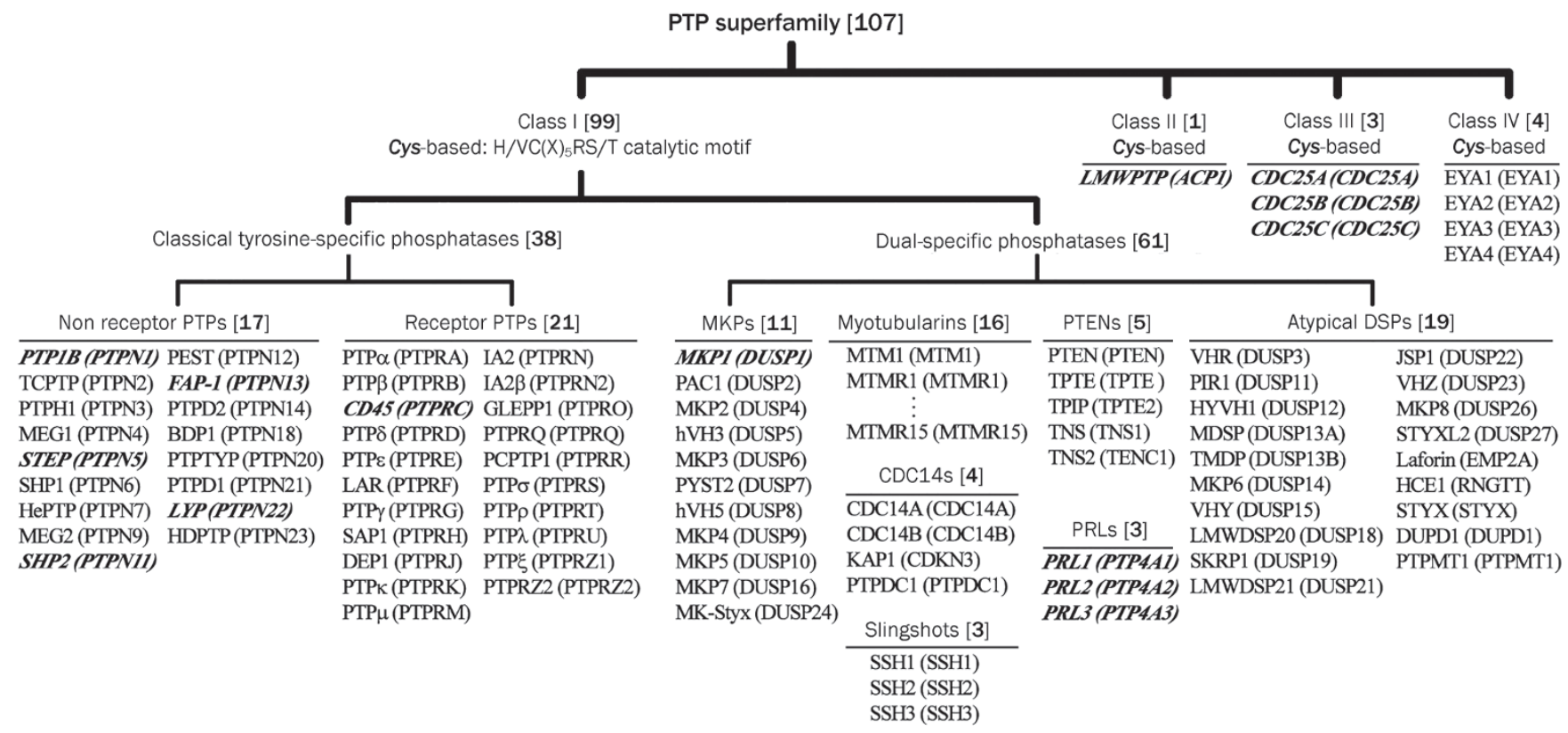

Figure 1. Human PTP classification. The gene encoding individual PTPs is shown in parenthesis after the PTP name. PTPs discussed in this review are highlighted in italic and bold font. 


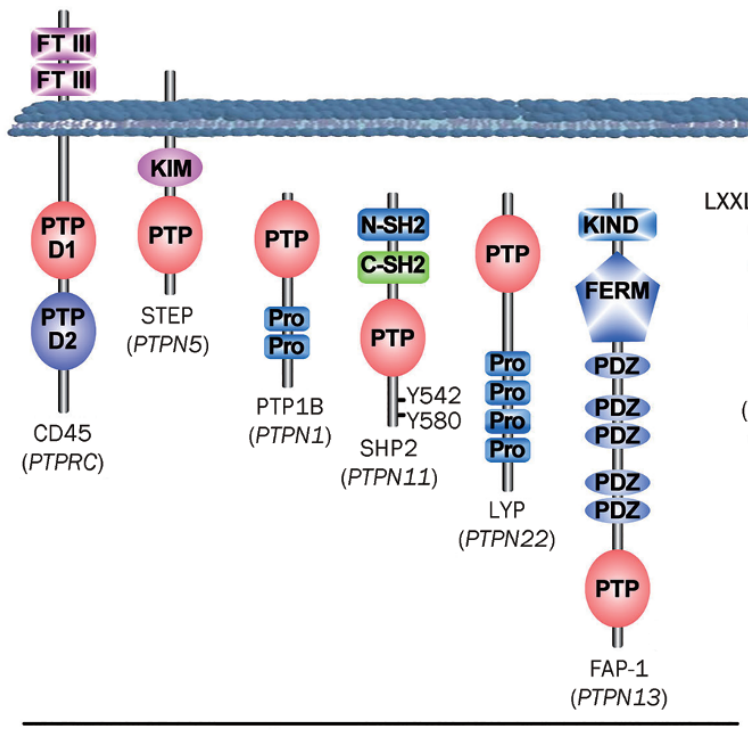

Classical PTPS

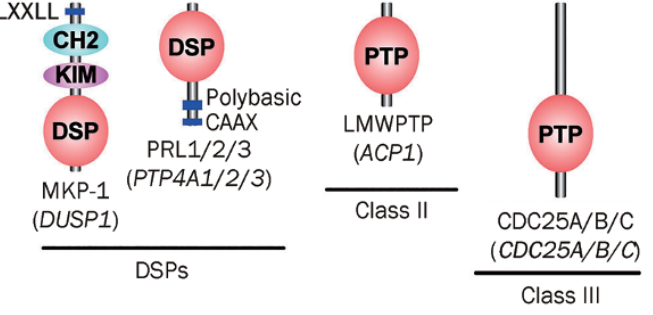

PTP: protein tyrosine phosphatase domain DSP: dual specificity phosphatase domain FT III: fibronectin type III-like domain KIND: kinase non-catalytic C-lobe domain FERM: F: 4.1 protein; E: ezrin; R, radixin; $M$, mosesin PDZ: acronym of three proteins: PSD95, DIg1, Zo-1 KIM: kinase interaction motif Pro: proline-rich motif SH2: Src homology-2 domain $\mathrm{CH} 2$ : Cdc25 homology domain

Figure 2. The schematic PTP structure discussed in this review.

PTP1B has been considered a novel drug target for type 2 diabetes and obesity. Many pharmaceutical companies, including Abbott, Novo Nordisk, AstraZeneca, Eli Lilly, Merck, Novartis, Incyte, Wyeth, and ISIS, have shown strong interest in PTP1B ${ }^{[25,26]}$. The combined efforts in developing PTP1B inhibitors have generated at least 4 drug candidates in clinical trials, including ertiprotafib, ISIS 113715, ISIS-PTP1B $\mathrm{B}_{\mathrm{R} x}$, and trodusquemine (Figure 4A) ${ }^{[26]}$. Notably, ISIS 113715 has been shown to improve glucose regulation and reduce LDL levels in type 2 diabetes patients in a phase 2 clinical trial. The more potent candidate ISIS-PTP1B $\mathrm{Rx}_{\mathrm{Rx}}$ will replace ISIS 113715 for further development, which aims to help patients whose disease is inadequately controlled by insulin and who are unresponsive to existing oral drugs.

Given its function in dephosphorylation of receptor tyrosine kinases, which are known to induce oncogenic signalling, PTP1B has also been regarded as a potential tumor suppressor. However, recent studies have revealed that PTP1B can promote tumorigenesis ${ }^{[27]}$. For example, PTP1B has been shown to activate c-Src in breast cancer cell lines by dephosphorylating its negative regulatory residue $\mathrm{Y} 530^{[28]}$ (Figure 3A). PTP1B can also activate the Ras-Raf-ERK oncogenic signaling pathway, most likely by dephosphorylating the scaffold protein p62Dok, which binds and activates p120RasGAP ${ }^{[29]}$ (Figure $3 \mathrm{~A})$. Moreover, PTP1B overexpression has been recorded in $72 \%$ of 29 human breast cancer samples examined, in comparison to healthy controls ${ }^{[30]}$. Its overexpression was detected in all stages of tumor development, and it correlated with ERBB2 overexpression, a frequently amplified receptor tyrosine kinase in breast cancer.

To understand the interplay between PTP1B and ERBB2 and to define PTP1B's role in breast cancer tumorigenesis, mice expressing an activated $E R B B 2$ gene were crossed with PTPN1-null mice ${ }^{[31,32]}$. Compared to control mice, PTPN1-null mice had a significant delay in tumor onset and a decreased rate of lung metastasis. Delayed tumor onset and decreased metastasis were also observed after treatment with a small molecule PTP1B inhibitor. Although the mechanism underlying PTP1B deletion or inhibition in tumor development remains unclear, these data indicate that $\mathrm{PTP} 1 \mathrm{~B}$ is functionally linked to ERBB2 and plays a positive role in breast cancer tumorigenesis. Recently, PTP1B overexpression was reported in colorectal cancer tissues, and its expression correlated with tumor differentiation, tumor invasion, lymph node metastasis, and TNM stage, which suggest that PTP1B may also play a positive role in colorectal cancer ${ }^{[33]}$. Therefore, PTP1B inhibition may be a novel strategy to treat these major human cancers.

\section{SHP2 in cancer}

The Src homology-2 (SH2) domain-containing phosphatase 2 (SHP2) encoded by the PTPN11 gene is a 593 amino acid classical non-receptor PTP. It has two tandem N-terminal SH2 domains (N-SH2, C-SH2), a catalytic PTP domain, a C-terminal tail with two tyrosine phosphorylation sites (Y542 and Y580) and a proline-rich region (Figure 2) ${ }^{[34,35]}$. SHP2's N-SH2 domain blocks access of SHP2's substrates by binding to its active site pocket at resting state ${ }^{[36]}$. However, upon growth factor or cytokine stimulation, the N-SH2 domain preferentially binds to tyrosine-phosphorylated proteins, such as receptor tyrosine kinase or scaffold proteins, to open up the phosphatase active site for catalysis. SHP2 is a positive regulator of the growth factor-mediated Ras-Raf-ERK pathway, and its phosphatase activity is essential for Ras-Raf-ERK 
pathway activation ${ }^{[35]}$. Several presumptive mechanisms have been proposed for its positive effect on ERK activation (Figure 3B), as follows: SHP2 could dephosphorylate the RasGAP binding site on RTK and/or Gab1 to prolong Ras activation ${ }^{[37] \text {; }}$ it could also dephosphorylate CSK binding sites on Paxillin to sequentially activate Src and Ras ${ }^{[38]}$; SHP2 may mediate the dephosphorylation of the negative Ras regulator Sprouty to activate the Ras-ERK signaling pathway ${ }^{[39,40]}$; finally, SHP2 could act as an adapter in Grb2/SOS complex recruitment, leading to Ras activation ${ }^{[41]}$. Moreover, SHP2 has been found to regulate PI3K-AKT, a well recognized oncogenic pathway, and SHP2 can regulate it in a ligand- and cell-dependent manner ${ }^{[22,43]}$. In addition, SHP2 has been indicated in JAK/STAT, JNK, and NF-KB signaling, which also have strong associations with various human cancers ${ }^{[44]}$.

A

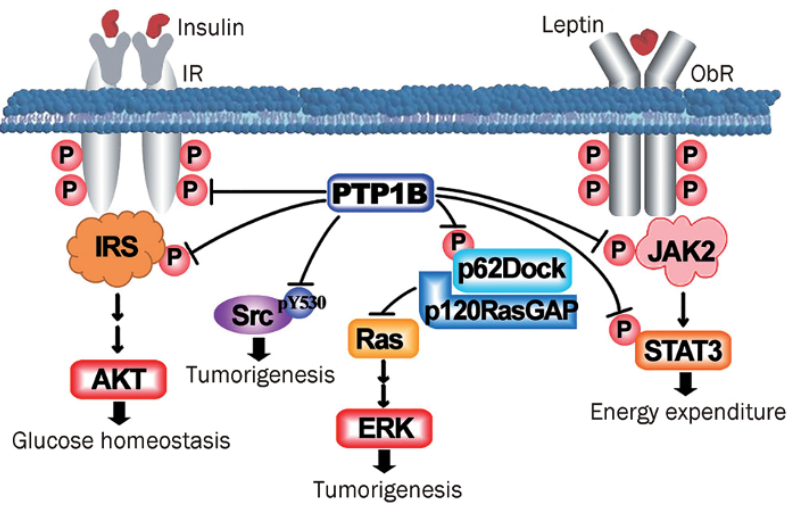

C

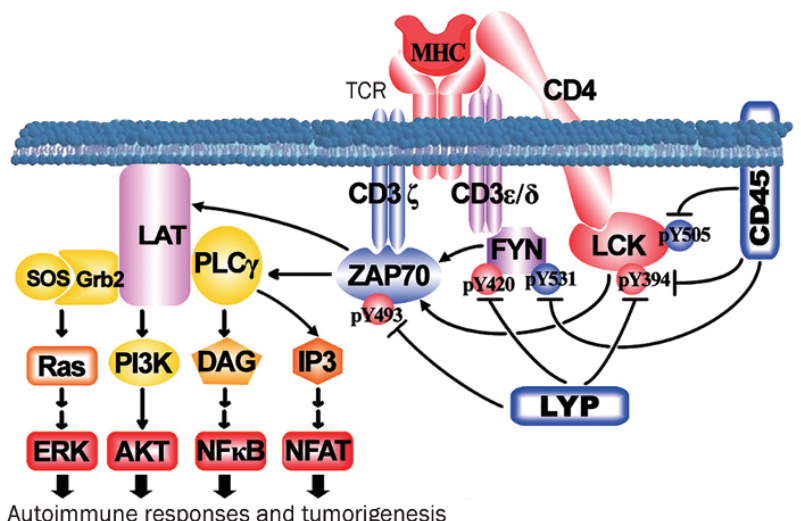

Clinical studies have shown that SHP2 mutations broadly exist in patients with Noonan Syndrome (NS), juvenile myelomonocytic leukemia (JMML), acute myelogenous leukemia (AML) and solid tumors ${ }^{[35,44-46]}$. Not surprisingly, many mutations lie between the N-SH2 and PTP domain, disrupting their intramolecular interactions ${ }^{[44]}$ and leading to constitutive SHP2 activation. Specifically, SHP2 germ-line mutations are present in $50 \%$ of NS patients, and SHP2 somatic mutations are present in $35 \%$ of sporadic JMML patients. The high incidence of SHP2 mutations indicate that it is likely a causative gene in these two diseases. Indeed, the SHP2 D61G mutation in mice phenocopies human NS, exhibiting characteristics such as smaller body size, serious cardiac defects, and reduced skull length ${ }^{[47]}$. Mice expressing JMML-linked SHP2 mutations (D61Y, D61G) exhibit myeloproliferative disorders similar to

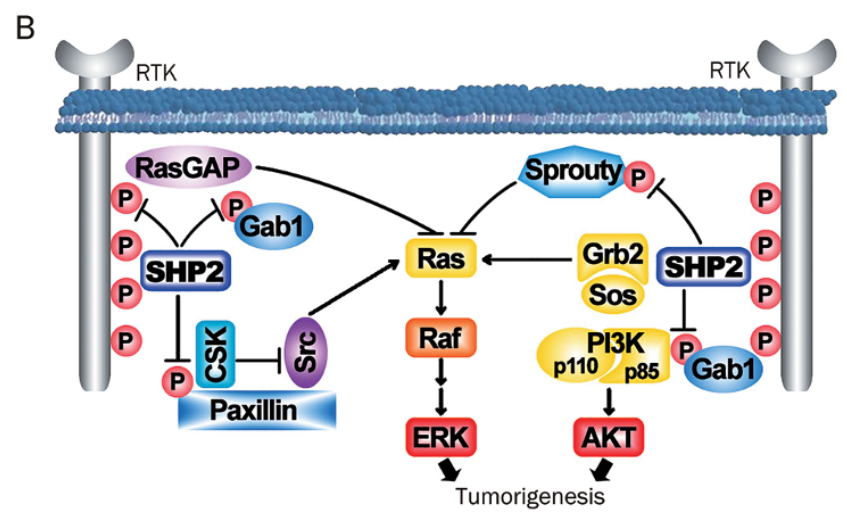

D

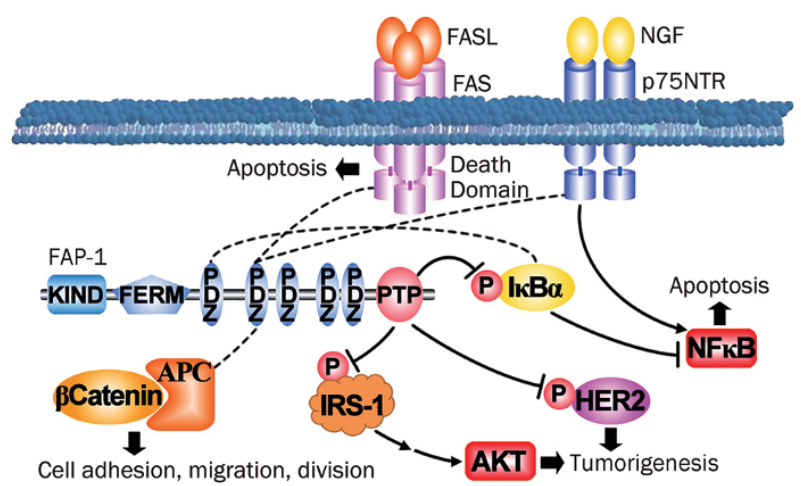

$\mathrm{E}$

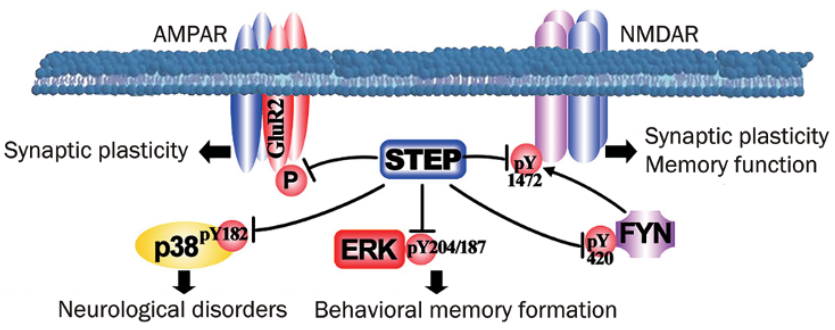

Figure 3. The physiological/pathological signal pathways involving PTP1B (A), SHP2 (B), LYP and CD45 (C), FAP-1 (D), and STEP (E). Arrow represents positive regulation. T-bar represents dephosphorylation if it points to a phosphate group or specific pY, otherwise it represents negative regulation. Dashed lines in panel (D) represent binding interaction. See the text for regulation details. 
those observed in JMML patients, including myeloid expansion, increased myeloid precursors, and granulocyte and macrophage tissue infiltration ${ }^{[48]}$. Human JMML characteristics include myeloid colony growth without exogenous cytokine stimulation and bone marrow cell hypersensitivity to granulocyte-macrophage colony stimulating factor (GM-CSF) ${ }^{[49]}$. Expression of JMML mutations D61Y and E76K in mouse bone marrow-derived hematopoietic progenitor cells promotes cell cycle progression in the presence of low level GM-CSF and cell survival in minimal media conditions ${ }^{[50,51]}$, supporting a positive role for SHP2 in promoting JMML. It was observed that pharmacological SHP2 inhibitors (eg, II-B08 ${ }^{[52]}$, cryptotanshinone ${ }^{[53]}$, and \#220-324 $4^{[54]}$ in Figure 4B) blocked the proliferation of patient-derived bone marrow low density mononuclear cells ${ }^{[52]}$, mouse myeloid progenitor cells, and leukemic cells $^{[53,54]}$ expressing the SHP2-activating mutation E76K. In addition, SHP2 phosphatase activity is required for oncogenic KIT-induced myeloid cell growth and survival, and genetic deletion or pharmacological inhibition of SHP2 can inhibit myeloid cell growth. SHP2 inhibitor alone or in combination with a PI3K inhibitor can prolong the survival of transplanted mice $^{[55]}$.

A recent report has shown that SHP2 positively regulates HER2-positive and triple negative breast cancers, and SHP2 knockdown in MCF10A human breast epithelial cells blocks HER2/3-induced tumor cell invasion in a 3-D cell culture model ${ }^{[56]}$. Treatment with SHP2 shRNA ${ }^{\text {miRs }}$ can eradicate tumor-initiating cells and block tumor growth and metastasis in relevant xenograft mouse models ${ }^{[56]}$. Moreover, in the epidermal growth factor receptor (EGFR) inhibition-resistant lung cancer cell line H1975, SHP2 is required for EGF-stimulated ERK1/2 phosphorylation and cell proliferation. Additionally, SHP2 knockdown or inhibition is sufficient to reduce ERK1/2 activation and block cell growth. This SHP2 inhibitor (II-B08) also has remarkable anti-tumor activity in xenograft mice $^{[57]}$. Taken together, these data suggest that SHP2 is a bona fide proto-oncogene and that targeting SHP2 is a promising strategy for various cancer treatments, including AML, JMML, breast cancer, and lung cancer.

\section{LYP in autoimmune disease}

The PTPN22-encoded lymphoid-specific phosphatase (LYP) is a classical 807 amino acid non-receptor $\mathrm{PTP}^{[58]}$. It has an $\mathrm{N}$-terminal catalytic domain and a C-terminal region with 4 proline-rich motifs (P1-P4) (Figure 2). LYP protein expression is restricted to hematopoietic tissues such as thymocytes and mature B cells and T cells. LYP is a strong T cell receptor (TCR) signaling inhibitor, which mediates important immune
A<smiles>Cc1cc(-c2c3ccccc3c(Br)c3sc(C)c(C)c23)cc(C)c1O[C@@H](Cc1ccccc1)C(=O)O</smiles>

Ertiprotafib
ISIS 113715 sequence: 5'-GCTCCTTCCACTGATCCTGC-3' ISIS PTP1B ${ }_{\mathrm{Rx}}$ sequence: 5'-AATGGTTTATTCCATGGCCA-3'

Either inhibitor is a 20-mer antisence oligonucleotide with above sequence and the following modifications: 1) Either $5^{\prime}$ or $3^{\prime}$ wing consists of five nucleosides and each nucleoside comprises a 2'-0-methoxyethyl sugar;

2) Ten deoxynucleosides are positioned between $5^{\prime}$ and $3^{\prime}$ wing;

3) All cytosines are 5-methylcytosines;

4) Each internucleoside linkage is phosphorothioate linkage

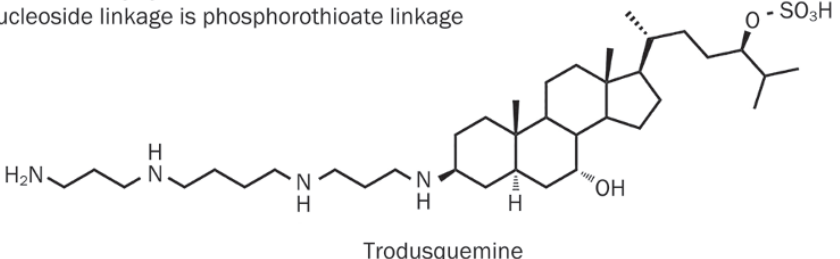

B<smiles>Cn1c(-c2ccccc2)c(/C(=C/NCCC(=O)Nc2ccc(-c3ccccc3)cc2)N=N)c2cc(C(=O)O)c(O)cc21</smiles>

C<smiles>Cc1ccccc1N1C(=O)/C(=C/c2ccc(OCc3cccc(C(=O)O)c3)cc2)C(=O)NC1=S</smiles>

LVT-1

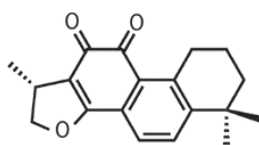

Cryptotanshinone<smiles>Cc1ccc2[nH]c(=O)c(C(c3nnnn3C3CCCC3)N3CCCC4(CCCCC4)C3)cc2c1</smiles>

Compound 4<smiles>Cc1cc(C)c2[nH]c3nc(SCC(=O)Cc4cccc5ccccc45)nnc3c2c1</smiles>

\#220-324

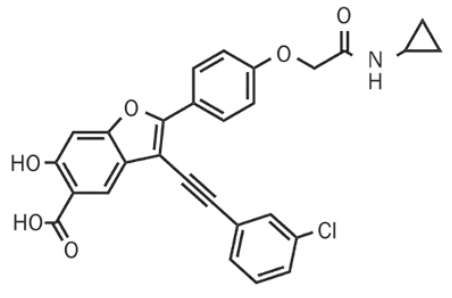

Compound $8 \mathrm{~b}$

Figure 4. The structure of PTP1B (A), SHP2 (B), and LYP (C) inhibitors mentioned in this review. 
responses ${ }^{[59-61]}$. As shown in Figure 3C, LYP dephosphorylates tyrosine residues in the activation loop of the Src family kinases LCK (Y394) and FYN (Y420), and ZAP70 (Y493), which contributes to TCR signaling activation ${ }^{[62,63]}$. LYP can also bind C-terminal Src kinase (CSK) through its proline rich P1 region and CSK's SH3 domain ${ }^{[64-66]}$. The LYP-CSK association might promote LYP's function in inhibiting $\mathrm{T}$ cell activation, as CSK can phosphorylate negative regulatory tyrosine residues in LCK (Y505) and FYN (Y531) ${ }^{[62,63]}$. LYP-null mice have elevated memory $\mathrm{T}$ cell activation and sustained TCR-induced phosphorylation of LCK (Y394) and ZAP70, although naive $\mathrm{T}$ cell functions remain normal ${ }^{[67]}$. These mice also spontaneously develop germinal centers with increased serum antibody levels. These results are consistent with cellular studies and suggest that LYP negatively regulates $\mathrm{T}$ cell development and function.

Importantly, a single-nucleotide polymorphism (SNP) (C1858T) in the PTPN22 gene is associated with type 1 diabetes (T1D) in many populations ${ }^{[60,61,68,69]}$. Autoimmune diseases are caused by abnormal immune responses against normal organs or tissues. In this case, T1D is the result of an autoimmune response of cytotoxic CD8 and CD4 positive T cells targeting insulin-producing $\beta$-cells. The C1858T LYP SNP has also been linked to other autoimmune diseases, such as rheumatoid arthritis ${ }^{[70,71]}$, Graves disease ${ }^{[72,73]}$, myasthenia gravis ${ }^{[74]}$, and systemic lupus erythematosu ${ }^{[75]}$, suggesting that LYP is a general susceptibility gene in both systemic and organ-specific autoimmune diseases.

The C1858T SNP in the PTPN22 gene encodes a mutant R620 LYP enzyme, which is 1.5 times more active than wildtype enzyme ${ }^{[76]}$. The mutation falls within the P1 proline-rich region, which disrupts the interaction between the P1 region and the SH3 domain, severely impairing LYP-CSK complex formation ${ }^{[64-66,76]}$. Interestingly, the R620W mutant more effectively inhibits T cell signaling compared to wild-type LYP in human $\mathrm{T}$ cells and Jurkat $\mathrm{T}$ cells ${ }^{[76]}$, which is contradictory to earlier notions that LYP cooperates with CSK to downregulate TCR signaling ${ }^{[62,63]}$. However, recent studies demonstrated that LYP forms a complex with CSK in resting T cells; upon TCR stimulation, LYP dissociates from CSK, resulting in increased LYP partition to lipid rafts, where it dephosphorylates substrates such as LCK and ZAP70 to downregulate TCR signaling ${ }^{[77]}$. In contrast, the R620W mutant cannot bind CSK and is therefore recruited to lipid rafts in the resting state. This uncontrolled TCR downregulation produces a gain-offunction phenotype and causes various human autoimmune diseases $^{[77]}$. PTPN22 knock-in mice have been generated to express the analogous $\mathrm{R} 619 \mathrm{~W}$ mutation ${ }^{[78,79]}$. As the mice age, they exhibit effector $\mathrm{T}$ cell expansion and transitional, germinal center, and B cell expansion, resulting in autoantibody development and systemic autoimmunity. These mice demonstrate the relevance of the LYP C1858T SNP in the increased risk of autoimmune diseases. Moreover, LYP pharmacological inhibitors (eg, LVT-1 ${ }^{[77]}$, Comp $4^{[80]}$, and Comp $8 \mathbf{b}^{[82]}$ in Figure $4 \mathrm{C}$ ) are very effective in promoting $\mathrm{T}$ cell activation ${ }^{[77,80]}$ and enhancing LYP-mediated signaling in thymocytes and bone marrow-derived mast cells ${ }^{[81,82]}$. In a passive systemic anaphylaxis mouse model, LYP inhibitors reduce calcium-mediated transcription and degranulation in mast cells and block anaphylaxis, highlighting the great therapeutic potential of LYP inhibitors in autoimmune disease treatment ${ }^{[82]}$.

\section{CD45 in autoimmune disease and cancer}

CD45 was studied decades ago as a cell surface glycoprotein $^{[83,84]}$. After the identification of mammalian PTP1B, sequence comparison indicated that CD45 has two tandem PTP domains in its cytosolic tail. CD45 was then classified as a class I receptor-like PTP ${ }^{[85]}$. CD45 is encoded by PTPRC and has a molecular weight between 170 and $220 \mathrm{kDa}$ with a highly glycosylated extracellular region, a single transmembrane domain, and two PTP domains D1 and D2 (Figure 2). The D1 PTP domain is catalytically active, but its activity requires the presence of the inactive D2 domain ${ }^{[86]}$. Many CD45 isoforms are generated by alternative splicing, and they primarily differ in their extracellular regions ${ }^{[87]}$. CD45 is expressed in the hematopoietic lineage such as $\mathrm{T}$ and $\mathrm{B}$ cells, and it is estimated to occupy up to $10 \%$ of total cell surface area, indicating its abundance in these cells ${ }^{[88]}$.

CD45 plays a critical role in T cell receptor and B cell receptor signaling, and Src family kinase LCK and LYN are wellcharacterized CD45 substrates in T cells and B cells, respectively ${ }^{[89-91]}$. LCK's kinase activity is required for TCR signaling, and it phosphorylates the TCR complex and activates ZAP70 to initiate a T cell activation cascade (Figure 3C). CD45 dephosphorylates the LCK Y505 residue, which negatively regulates LCK activity when phosphorylated, to positively regulate $\mathrm{T}$ cell activation. This is consistent with cellular studies in which CD45-deficient cells have increased levels of LCK Y505 phosphorylation ${ }^{[92-94]}$. CD45-null mice have T cell defects that can be rescued by an LCK Y505F mutant ${ }^{[95]}$. Interestingly, LCK is hyperphosphorylated at site Y394 in CD45 deficient cells ${ }^{[89,96,97]}$, which is a positive regulatory residue and enhances LCK kinase activity when phosphorylated. These data suggest that CD45 can also downregulate LCK activity. It has been suggested that Y505 phosphorylation affects $\mathrm{T}$ cell signaling at low CD45 levels, while its effect is counterbalanced by Y394 phosphorylation at higher CD45 levels ${ }^{[98]}$. Similarly, CD45 regulates LYN in B cells where it dephosphorylates the negative regulatory Y508 residue and the positive regulatory Y397 residue, thus controlling LYN kinase activity $^{[99-101]}$. B cell development and B cell signaling responses are reduced in CD45-null mice upon ligation, including altered proportion of B cell subsets. Other reported CD45 substrates include FYN and JAK in T cells ${ }^{[94,102]}$, HCK and LYN in macrophages ${ }^{[103]}$, and LYN, HCK and FYN in dendritic cells ${ }^{[104]}$.

Given its important role in immune signaling pathways, CD45 has been linked to many autoimmune diseases ${ }^{[105]}$. For example, a SNP in CD45's exon 4 causes a C77G mutation and is associated with increased incidence of multiple sclerosis ${ }^{[106-108]}, \operatorname{HIV}^{[109]}$, autoimmune hepatitis ${ }^{[110]}$, and systemic sclerosis ${ }^{[111]}$. The C77G mutation disrupts an exonic splicing silencer, which results in high molecular weight CD45 iso- 
form expression (eg, CD45RA, which has higher CD45 activity in cells due to decreased ability to form homodimers ${ }^{[112]}$. Another SNP in exon 4 causes the C59A mutation and has also been reported to interfere with splicing in several multiple sclerosis multiplex family members, which results in CD45RA expression in memory $\mathrm{T}$ cells ${ }^{[113]}$. In contrast, a SNP in exon 6 causes the A138G mutation and has a protective effect in hepatitis B infection and autoimmune Graves' thyroiditis. This SNP promotes exon skipping, which results in increased expression of the low molecular weight isoform CD45RO ${ }^{[114,115]}$. In addition, the E613R mutation in mouse CD45 is thought to disrupt homodimer formation to cause aberrant CD45 activity, and its expression produces a phenotype characterized by lymphoproliferative syndrome and autoimmune diseases ${ }^{[16]}$. These genetic studies indicate a dose-response curve between CD45 and human autoimmune diseases, suggesting that CD45 is a good drug target for autoimmune disease treatment.

CD45 is broadly expressed and has been used in antibodymediated therapy against hematopoietic malignancies ${ }^{[117]}$. Earlier studies have demonstrated that a CD45 antibody killed CD45-positive leukemic cells via antibody-dependent and host-cell-mediated cytotoxicity. However, a more general strategy is CD45-based radioimmunotherapy in which the CD45 antibody is conjugated to a radioactive agent, such that a high dose of radiation is specifically delivered to hematopoietic tissue. In a pilot study ${ }^{[118]},{ }^{131}$ I-coupled anti-CD45 was assessed in 44 patients with high-risk acute leukemia or myelodysplasia for marrow transplantation. Seven out of 25 treated patients with acute myeloid leukemia/myelodysplastic syndrome survived disease-free for 15 to 89 months (median, 65 months) post-transplantation. More recently, ${ }^{211}$ At-coupled anti-CD45 treatment prior to hematopoietic stem cell transplantation improved the median survival of leukemic mice in a dose-dependent fashion, and ${ }^{211}$ At-coupled antiCD45 faithfully localized to the marrow and spleen with minimal toxicity ${ }^{[119]}$. In addition, leukemia mouse models treated with anti-CD45 antibody-streptavidin conjugate and subsequent administration of ${ }^{213} \mathrm{Bi}$ - or ${ }^{90} \mathrm{Y}$-DOTA-biotin conjugate, survived leukemia-free for more than 100 days with minimal toxicity ${ }^{[120]}$. These data suggest that anti-CD45-based radioimmunotherapy is a highly effective approach for hematopoietic malignancy treatment.

\section{FAP-1 in cancer}

PTPN13-encoded Fas-associated phosphatase 1 (FAP-1, also named PTP1E, PTP-BAS and PTPL1) is a 2485 amino acid classical non-receptor PTP ${ }^{[121-123]}$. It contains a KIND domain, a FERM domain, five PDZ domains, and a PTP catalytic domain (Figure 2). The FERM domain binds to phosphatidylinositol 4,5-biphosphate, which targets FAP-1 to juxtamembrane regions $^{[124]}$, PDZ domains are responsible for protein-protein interactions ${ }^{[125]}$, but the KIND domain has not been well-studied. The structure of FAP-1's catalytic domain is very similar to PTP1B in overall folding ${ }^{[126,127]}$.

One of the most important discoveries regarding FAP-1 is that it interacts with the cytosolic portion of the FAS recep- tor $^{[128]}$, a tumor necrosis factor (TNF) receptor or death receptor whose activation leads to cell apoptosis, and negatively regulates FAS-initiated apoptosis (Figure 3D). Studies have shown that FAS receptor's C-terminal tripeptide Serine-Leucine-Valine (SLV) sequence is sufficient to bind FAP-1's second PDZ domain ${ }^{[129,130]}$, and by doing so, FAP-1 inhibits FAS receptor export to the cell surface ${ }^{[131]}$. FAP-1 can also bind the p75NTR intracellular domain, another TNF receptor family member, through the second PDZ domain, and negatively regulate p75NTR-mediated NF-kB suppression and pro-apoptotic signaling $^{[132]}$ (Figure 3D). In addition, FAP-1 binds the very C-terminus of the tumor suppressor Adenomatous Polyposis Coli (APC) through its second PDZ domain, and APC is a $\beta$-catenin-associated scaffold ${ }^{[133]}$. Thus, FAP-1 may indirectly modulate $\beta$-catenin tyrosine phosphorylation and regulate cell adhesion, migration, and division (Figure 3D). Other reported FAP-1 binding partners include IkBa, RhoGAP1, EphrinB1, and TRPM2 ${ }^{[125]}$. I $\mathrm{BBa}$ is the only FAP-1 binding protein that is also dephosphorylated by FAP-1, suggesting that it is a putative FAP-1 substrate ${ }^{[134,135]}$. IKBa tyrosine phosphorylation is a key element in NF- $\mathrm{KB}$ activation; therefore, FAP-1 may regulate NF-kB activation. FAP-1 specifically dephosphorylates IRS-1 and blocks insulin-like growth factor-induced PI3K/AKT signaling pathway ${ }^{[136]}$. In addition, FAP-1 interacts with and dephosphorylates HER2 and inhibits growth factorinduced HER2 signaling ${ }^{[137]}$. FAP-1-deficient mice are generally healthy but have increased $\mathrm{T}$ cell activity such as cytokine elaboration and improved host defense against K pneumonia lung infection, as evidenced by the 35 -fold less living bacteria in their lungs compared to wild-type controls ${ }^{[138]}$. Independent knockout studies have shown that FAP-1-null mice develop normally but have a mild deficiency in motor neuron repair, and significantly reduced retinal glial numbers in cultures from lens-lesioned knockout mice compared to wild-type controls $^{[139,140]}$.

Because FAP-1 negatively regulates FAS-initiated cell apoptosis, it has been suggested to positively regulate tumorigenesis. FAP-1 inhibits FAS-mediated apoptosis in pancreatic adenocarcinoma $^{[141,142]}$ and melanoma ${ }^{[131]}$, and FAP-1 and FAS expression highly correlate with cell survival in ovarian cancer $^{[143]}$, colon cancer ${ }^{[144]}$, head/neck cancer ${ }^{[145]}$, hepatocellular carcinoma and hepatoblastoma ${ }^{[146,147]}$. Ewing's Sarcoma family of tumors (ESFT) is characterized by the formation of chimeric fusion protein EWS-FLI1, which is an oncogenic transcriptional factor that promotes tumorigenesis ${ }^{[148]}$. FAP-1 has been identified as a EWS-FLI1 oncogenic fusion protein transcriptional target ${ }^{[149]}$. FAP-1 is highly expressed in ESFT cells and patient tumor samples and is required for ESFT transformed phenotype maintenance ${ }^{[150-152]}$. Reduction of FAP-1 in ESFT cells significantly reduces monolayer and soft-agar cell growth and increased sensitivity to etoposide-induced apoptosis $^{[149]}$

Studies have shown that FAP-1 expression is increased in SW480 colon carcinoma cells after treatment with the chemotherapeutic agent oxaliplatin. siRNA knockdown of FAP-1 reduces cell proliferation and promotes oxaliplatin-induced 
cell apoptosis, suggesting that FAP-1 inhibition increases oxaliplatin efficacy in colon carcinoma treatment ${ }^{[153]}$. Tumor progression shares many characteristics with epithelial-tomesenchymal transition (EMT), and cells undergoing EMT are more resistant to apoptosis ${ }^{[154]}$. The miR-200 family of miRNAs is a fundamental marker and powerful regulator of EMT, as it maintains the epithelial phenotype by suppressing EMTinducing transcription factor ZEB1 and ZEB2 expression ${ }^{[155]}$. miR-200 family members are frequently downregulated during early malignant transformation but are subsequently upregulated in advanced stages in several human cancers ${ }^{[156]}$. FAP-1 has been identified as a miR-200c target, and it is responsible for the reduced sensitivity to FAS-mediated apoptosis in cells in miR-200-inhibited cells, providing a mechanism by which cancer cells with reduced miR-200 expression are less sensitive to FAS-mediated apoptosis ${ }^{[157]}$

In contrast, there is also evidence that FAP-1 may be a tumor suppressor. For example, reduced PTPN13 mRNA expression by promoter hypermethylation or allelic loss has been observed in gastric and hepatocellular carcinomas ${ }^{[158,159]}$, and FAP-1 knockdown enhances PLC5 cell proliferation ${ }^{[159]}$. In a large-scale mutational PTP analysis in colorectal cancers, 19 PTPN13 mutations were identified, and 7 of them were in the PTP domain, which may impair FAP-1's catalytic activity ${ }^{[160]}$. Nevertheless, with 8 domains, FAP-1 is among the largest intracellular PTPs, suggesting that it has multiple functions and may play positive or negative roles in a context-dependent manner. Thus, FAP-1 is a promising chemotherapy target for irradiation-resistant cancer.

\section{STEP in neurological diseases and disorders}

Striatal-enriched protein tyrosine phosphatase (STEP) is encoded by PTPN5 and is a classical and brain-specific PTP, with two alternative spliced isoforms $\left(\right.$ STEP $_{46}$ and STEP 61 ). $\mathrm{STEP}_{46}$ is cytoplasmic, while $\mathrm{STEP}_{61}$ localizes to the postsynaptic density and endoplasmic reticulum ${ }^{[161-163]}$. STEP has a phosphatase domain similar to all other PTPs and a kinase interaction motif (KIM), which is also present in HePTP and PTP-SL (Figure 2). The KIM domain allows STEP to interact with MAPKs, such as ERK and p38, and STEP dephosphorylates tyrosine residues in their activation loops to reduce ERK and p38 activation. ERK activity is significantly higher in the striatum, CA2 region of the hippocampus, and central and lateral nuclei of the amygdala in STEP-null mice. Cultured neurons from STEP-knockout mice have increased ERK phosphorylation upon synaptic stimulation compared to neurons from wild-type controls $^{[164]}$. The p38a.STEP complex structure has been solved by NMR and small-angle X-ray scattering data, providing a molecular basis of STEP recognition of $\mathrm{p}^{38 \mathrm{a}^{[165]}}$. Notably, ERK is a very important player in synaptic and neuronal plasticity and is an essential component in signaling pathways that regulate behavioral memory formation ${ }^{[166]}$, and p38a has been implicated in the neurological disorder pathogenesis $^{[167,168]}$.

STEP can mediate DHPG (dihydroxyphenylglycine)-induced AMPAR (a-amino-3-hydroxy-5-methyl-4-isoxazolepropionic acid receptor) internalization (Figure 3E), a central process in synaptic plasticity. DHPG stimulation significantly increases STEP protein expression, which is likely responsible for GluR2 (an AMPAR member) dephosphorylation and internalization. STEP-inactive mutants abolish AMPAR internalization ${ }^{[169]}$. In STEP knockout mice, GluR1 and GluR2 baseline synaptic expression is increased compared to wild-type littermates, and DHPG-stimulated GluR1 and GluR2 internalization is also abolished in these mice ${ }^{[169]}$. STEP can also regulate NMDAR ( $N$-methyl- $D$-aspartate receptor) (Figure $3 \mathrm{E})$, a glutamate receptor involved in synaptic plasticity and memory function. STEP blocks NMDAR exocytosis by dephosphorylating and inactivating Y420 of FYN kinase ${ }^{[170]}$. FYN positively regulates NMDAR exocytosis to neuronal surfaces by phosphorylating Y1472 in NR2 $B^{[171]}$. Alternatively, STEP can promote clathrindependent NMDAR endocytosis by directly dephosphorylating Y1472 of NR2B ${ }^{[172,173]}$.

STEP has been linked to many neurological diseases and disorders, including Alzheimer's disease (AD), Huntington's disease (HD), schizophrenia, fragile $\mathrm{X}$ syndrome (FXS), hypoxic-ischemic brain injury, depression, and alcohol use disorders ${ }^{[174]}$. For example, STEP protein level and activity are upregulated in the prefrontal cortex of AD patients and in the cortex of an $\mathrm{AD}$ mouse model. Interestingly, $\mathrm{A} \beta$-enriched medium was sufficient to increase STEP expression and to decrease NR1 and NR2B surface expression in wild-type cultured cortical neurons and cortical slices, but not in STEP knockout cultures. These data indicate that STEP is required for $A \beta$-induced NMDAR endocytosis ${ }^{[173,175]}$. Schizophrenia is a mental disorder with behavioral and cognitive deficits partially due to the disruption of glutamatergic signaling. Schizophrenia patients have significantly higher STEP expression in the postmortem anterior cingulated cortex and dorsolateral prefrontal cortex, and similar observations have been made in mice treated with the psychotomimetics MK-801 and phencyclidine $(\mathrm{PCP})^{[176]}$. In contrast, STEP knockout mice are less sensitive to acute and chronic PCP administration in terms of their locomotor and cognitive effects ${ }^{[176]}$. Furthermore, several typical and atypical antipsychotic medications for schizophrenia treatment can act through STEP, as antipsychotic treatment of mice induces protein kinase A-mediated STEP 61 phosphorylation and inactivation and increased GluN1/GluN2B receptor surface expression $^{[176]}$.

It has been suggested that STEP proteasome degradation is blocked in both AD and schizophrenia, leading to STEP accumulation and glutamate receptor internalization, and further contributing to AD and schizophrenia pathogenesis ${ }^{[173,176]}$. Alcohol is known to cause cognitive impairment and memory and learning disruption in alcohol abuse disorders, likely through hippocampal NMDAR inhibition. Interestingly, STEP mediates alcohol's inhibitory effects on neuronal NMDAR function. This is further supported by STEP knockout studies in which alcohol-induced NMDAR function and fearconditioned responses were not observed. However, STEP re-introduction into neuronal cultures and slices restored ethanol-induced biochemical and electrophysiological deficits ${ }^{[177]}$. 
Taken together, STEP is a potential novel drug target for the treatment of AD, schizophrenia, alcoholism and addiction, among other neurological diseases and disorders.

\section{MKP-1 in cancer and neurological disorders}

Mitogen-activated protein kinase phosphatases (MKPs) are a group of 11 dual-specificity protein phosphatases. All MKP members are structurally similar with a PTP domain at the C-terminus, a KIM domain for MAPK recognition, and an $\mathrm{N}$-terminal sequence for subcellular localization (Figure 2). As their name implies, MKPs interact with and dephosphorylate pThr and pTyr in MAPK's activation loop, including ERK, JNK, and p38, to downregulate MAPK activity ${ }^{[178]}$. MKP-1 was the first identified family member with 367 amino acids, and it is an immediate early gene ${ }^{[179,180]}$. It is ubiquitously expressed, but is expressed most highly in the heart, lungs and liver ${ }^{[179]}$. Its N-terminal LXXLL sequence allows exclusive MKP-1 nuclear localization ${ }^{[181]}$. MKP-1 preferentially dephosphorylates p38 and JNK and to a lesser extent, ERK (Figure $5 \mathrm{~A})^{[180,182-184]}$. Interestingly, MAPK activation can induce MKP-1 transcription upon growth factor stimulation or stress, creating a negative feedback regulation loop between MAPK and MKP-1 ${ }^{[185]}$. In addition, MKP-1-null mice are viable, fertile and have no phenotypic or histologic abnormalities ${ }^{[186]}$.

A

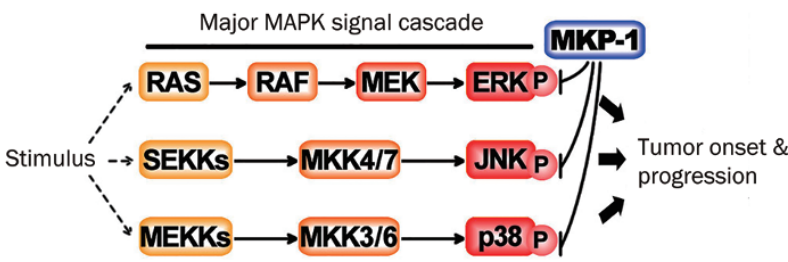

B

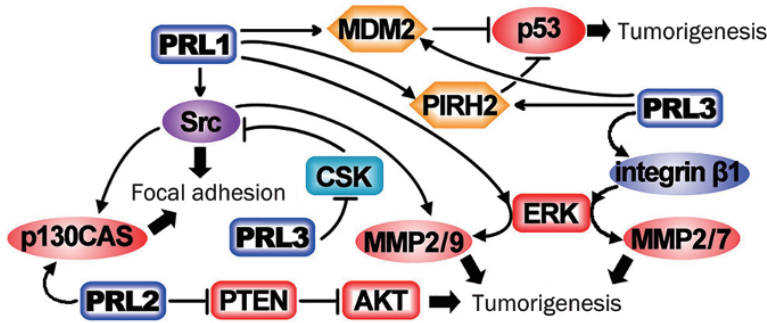

Figure 5. The physiological/pathological signal pathways involving MKP-1 (A) and PRL1/2/3 (B). Arrow represents positive regulation. T-bar represents dephosphorylation if it points to a phosphate group or specific $\mathrm{pY}$, otherwise it represents negative regulation. See the text for regulation details.

MKP-1 is well studied in human cancers because of its direct association with MAPK, which is a key regulator of cell proliferation, differentiation, survival, and apoptosis ${ }^{[187,188]}$. MKP-1 overexpression has been detected in many cancers, including colon, prostate, bladder, ovarian, breast, and NSCLC ${ }^{[189-194]}$. In prostate cancer, MKP-1 expression is inversely correlated with JNK activity and apoptotic marker expression ${ }^{[190,192]}$, and
MKP-1 overexpression is associated with resistance to FASinduced apoptosis in the prostate cancer cell line DU145 $5^{[195]}$. In breast cancer cells, MKP-1 overexpression protects against chemotherapy-induced apoptosis, including doxorubicin, mechlorethamine, and paclitaxel. In contrast, siRNA knockdown of MKP-1 sensitizes cells to chemotherapy-initiated apoptosis by increasing JNK activity ${ }^{[196]}$. Proteasome inhibition induces MKP-1 expression by decreasing JNK activity. MKP-1 knockdown also increases cell sensitivity to proteasome inhibitors $^{[197]}$. In a clinical study with 96 patients, MKP-1 overexpression correlates with likelihood of relapse compared to patients with normal MKP-1 levels ${ }^{[198]}$. In addition, MKP-1 is strongly expressed in NSCLC tumor tissues and the H-460 and $\mathrm{H}-23$ cell lines. siRNA knockdown of MKP-1 resulted in a ten-fold increase in cisplatin sensitivity ${ }^{[199]}$. Moreover, tumors induced by MKP-1 siRNA H-460 grow slower in xenograft mouse models and show increased cisplatin susceptibility compared to parental cell control tumors ${ }^{[199]}$. These results suggest that MKP-1 is an important cancer target that may increase the effects of chemotherapy.

MAPK is associated with memory and learning, neuronal plasticity and development ${ }^{[200]}$. As a MAPK regulator, MKP-1 may thus play important roles in many brain functions. MKP1 is a transcriptional c-Jun target, and MKP-1 antagonizes JNKdependent apoptosis in sympathetic neurons ${ }^{[201]}$. MKP-1 overexpression blocks JNK-mediated c-Jun phosphorylation and subsequent sympathetic neuron apoptosis, while MKP-1 knockdown enhances nerve growth factor (NGF) withdrawalinduced death. Loss of MKP-1 results in decreased numbers of superior cervical ganglion neurons at P1 during developmental sympathetic neuron death ${ }^{[201]}$. These results suggest that MKP-1 is part of a negative feedback loop to modulate MLK-JNK-c-Jun signaling. Neurotrophin brain-derived neurotrophic factor (BDNF) can induce MKP-1 expression to regulate outgrowth and activity-dependent remodeling of axonal arbors in vivo, which causes spatiotemporal JNK dephosphorylation and its substrates and contribute to microtubule destabilization ${ }^{[202]}$. Neurons from MKP-1 knockout mice cannot produce BDNF-induced axon branches. Because axonal arbor formation and maturation is strongly associated with increased synaptic connectivity and are positively regulated by BDNF, MKP-1 may play an important role in synaptogenesis. Furthermore, MKP-1 dysregulation may have deleterious effects on learning and memory, which depend on plasticity ${ }^{[203]}$.

MKP-1 is also a key factor in major depressive disorder (MDD) pathophysiology ${ }^{[204]}$. In rat and mouse models, hippocampal MKP-1 expression increases upon stress or viralmediated gene transfer, leading to depressive behaviors. Chronic treatment with antidepressants normalizes stressinduced MKP-1 expression and depressive behaviors ${ }^{[204]}$. It was observed that MKP-1 knockout mice are more resistant to stress compared to wild-type littermates, and this effect is mediated by increased ERK activity, consistent with studies that MEK-ERK signaling is essential for antidepressant responses $^{[204]}$. Moreover, MKP-1 expression is significantly 
increased in postmortem hippocampal tissues from 21 individuals with depression compared to samples from 18 healthy age, gender, tissue $\mathrm{pH}$ and postmortem interval-matched controls, indicating a direct clinical association between MKP-1 overexpression and depression ${ }^{[204]}$. Thus, MKP-1 may also be a novel and promising drug target for the treatment of depression and other mood disorders.

\section{PRLs in cancer}

PRLs (phosphates of regenerating liver) are a subclass of dual specific phosphatases with 3 similar members, PRL1, PRL2 and PRL3 ${ }^{[205]}$. PRLs have an N-terminal PTP catalytic domain, a C-terminal polybasic region, and a prenylation CAAX sequence (Figure 2), which is a unique feature to this subclass and is responsible for PRL plasma or intracellular membrane localization ${ }^{[206,207]}$. Given their similarities, PRLs act redundantly in many biological functions (Figure 5B). For example, both PRL1 and PRL3 regulate focal adhesion contact though Src activation, although PRL1 does so by enhancing Y419 phosphorylation in the kinase activation loop ${ }^{[208]}$, while PRL3 downregulates the negative Src regulator CSK, leading to a decrease in Y530 autoinhibitory Src phosphorylation ${ }^{[209]}$. PRL2 targets p130CAS signaling to regulate Src-independent focal adhesion contact ${ }^{[210]}$. PRL1 and PRL3 can downregulate the p53 tumor suppressor by stabilizing MDM2 and increasing PIRH2 transcription ${ }^{[211,212]}$, whereas PRL2 regulation of p53 has not been elucidated. In addition, PRL1 and PRL3 can both activate and promote matrix metalloproteinase (MMP) expression, extracellular secreted proteins with important roles in tumor metastasis. PRL1 upregulates MMP2 and MMP9 through Src and ERK activation ${ }^{[213]}$, whereas PRL3 upregulates MMP2 and MMP7, but not MMP9, via integrin $\beta 1$ and ERK pathways $^{[214]}$.

Given their role in regulating p53 and MMPs, PRLs may play important roles in human cancer pathophysiology $y^{[205,215,216]}$. For example, PRL1 is overexpressed in lung and pancreatic cancer cell lines with increased invasive properties, which are reversed by PRL1 knockdown ${ }^{[208,213,217,218]}$. PRL2 is overexpressed in pancreatic, breast and lung cancer, as well as pediatric AML. PRL2 expression levels are associated with tumor progression and poor $\operatorname{prognosis}^{[210,217,219,220]}$. In addition, PRL3 overexpression is widely found in cancers, including colon, breast, gastric, oral, cervix, and ovarian carcinomas, multiple myelomas and $\mathrm{AML}^{[215,221]}$. In colon cancer, PRL3 overexpression positively correlates to poor prognosis and liver metastasis ${ }^{[222]}$. Studies have shown that stable PRL3 expression increases cell motility and invasiveness and induces tumor formation and metastasis in mouse models ${ }^{[223]}$. In contrast, PRL3 siRNA knockdown blocks cell motility and metastasis, suggesting that PRL3 is a potential cancer treatment target ${ }^{[24,225]}$. PRL3 can upregulate PDGFR, Eph, and integrin receptor, as shown in a proteomic analysis of PRL3overexpressing HEK293 cells.

Phosphoproteomic data support the intracellular activation of an extensive signaling network normally governed by extracellular ligand-activated transmembrane growth factor, cyto- kine, and integrin receptors in PRL3-overexpressing cells ${ }^{[226]}$. Similarly, PRL3 induces EGFR hyperactivation and its downstream signaling pathways in multiple human cancers, contributing to cell growth, migration and tumorigenicity. PRL3overexpressing cancer cells are highly sensitive to oncogenic EGFR signaling, as they are sensitive to EGFR inhibiting treatment ${ }^{[227]}$. More recent studies of genetically modified mouse models demonstrate that PRL2 is required for several developmental processes (placenta, spermatogenesis, hematopoietic stem cell self-renewal) and reveal a novel mechanistic connection between PRL2 and PTEN ${ }^{[228-230]}$. Given the strong cancer susceptibility to subtle variations in PTEN levels, PRL2's ability to repress PTEN expression qualifies it as an oncogene and a novel target for anti-cancer agents. Taken together, PRLs are of great therapeutic importance as clinical predictive biomarkers for personalized medicine and novel drug targets for high metastatic potential cancers.

\section{LMWPTP in cancer and diabetes}

Low molecular weight protein tyrosine phosphatase (LMWPTP) has a single catalytic domain (Figure 2) with an approximate molecular weight of $18 \mathrm{kDa}$. It is the sole class II PTP member, and its overall sequence and 3D structures are different from the aforementioned higher molecular weight PTPs, with the exception of the conserved PTP signature motif (P-loop). LMWPTP is well conserved across many prokaryotic and eukaryotic species, suggesting that it may play fundamental roles throughout evolution ${ }^{[231]}$. There are 4 human LMWPTP isoforms, and 2 are catalytically active, namely IF1 and IF2 (or LMWPTP-A and LMWPTP-B) ${ }^{[232,233]}$. These two isoforms have very high sequence and structure similarity, and the minor difference exists in a flexible loop flanking the active site, which is thought to determine their physiological substrate specificity ${ }^{[234]}$. Our knowledge of human LMWPTPs is primarily from the study of IF1.

LMWPTP regulates many receptor tyrosine kinase and growth factor-induced signaling pathways, which control cell growth, differentiation and adhesion (Figure 6A). For example, phosphorylated PDGF receptor is a well-known LMWPTP substrate dephosphorylated on Y857 in its $\beta$ subunit $^{[235-237]}$, which is a regulatory residue for PDGF receptor kinase activity. LMWPTP also dephosphorylates Src kinase and STAT family transcription factors, and block their PDGF receptor-induced activation ${ }^{[238-240]}$. In addition, LMWPTP can dephosphorylate and inactivate $\mathrm{FAK}^{[241]}$ and p190RhoGAP ${ }^{[242]}$, which are involved in cell-extracellular matrix adhesion. More importantly, EphA2 is a preferred LMWPTP substrate in tumor cells ${ }^{[243-245]}$. EphA2 is a receptor tyrosine kinase overexpressed in many human cancers, especially in aggressive and metastatic types ${ }^{[243]}$. In contrast to PDGF receptor, EphA2 phosphorylation inhibits cell growth and migration, while its dephosphorylation induces oncogenic characteristics ${ }^{[246,247]}$. LMWPTP overexpression in epithelial cells induces colony formation in soft agar and promotes neoplastic transformation $^{[243]}$. LMWPTP-transfected NIH3T3 fibroblasts can induce larger fibrosarcomas in nude mice with higher proliferation 
A

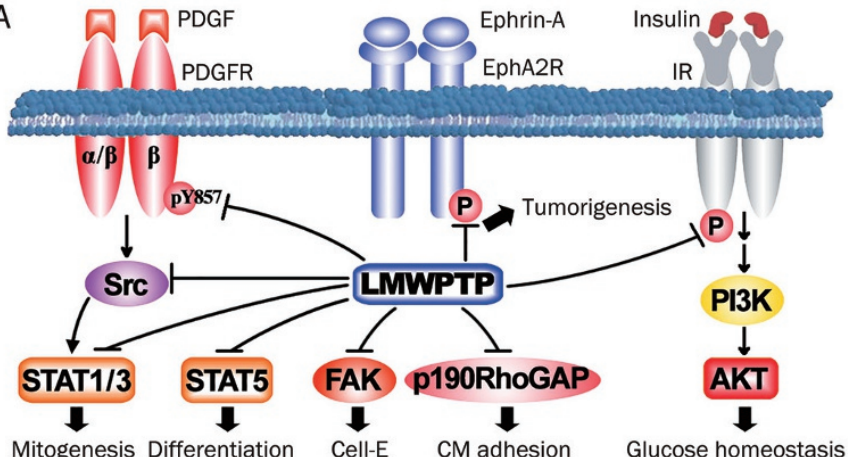

B

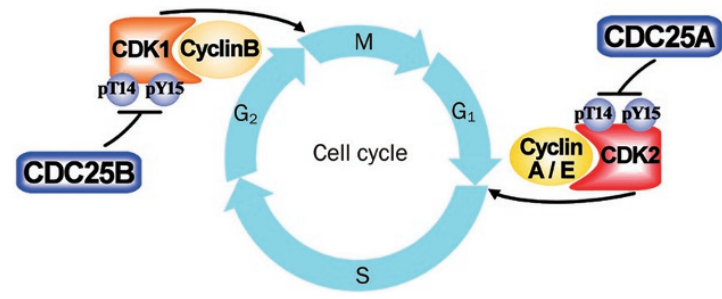

Figure 6. The physiological/pathological signal pathways involving LMWPTP (A) and CDC25 (B). Arrow represents positive regulation. T-bar represents dephosphorylation if it points to a phosphate group or specific $\mathrm{pY}$, otherwise it represents negative regulation. See the text for regulation details.

activity and greatly dephosphorylated EphA2 compared to mock-transfected controls. The opposite was true in dominant negative/inactive LMWPTP-transfected cells ${ }^{[244]}$. Because LMWPTP is overexpressed in many tumor types, LWMPTP and EphA2 may form an oncogenic axis to promote tumor initiation, progression and metastasis.

LMWPTP is also a key negative regulator of insulin signaling through tyrosine dephosphorylation of the insulin receptor (IR) $\beta$ subunits ${ }^{[248]}$. A study from Eli Lilly demonstrated that decreased LMWPTP expression by a specific antisense oligonucleotide (ASO) increases IR, PI3K, and AKT phosphorylation, thus sensitizing insulin signaling ${ }^{[249]}$. ASO treatment resulted in decreased plasma insulin, glucose, triglyceride and cholesterol levels, with improved glucose and insulin tolerance in mice ${ }^{[249]}$. Interestingly, LMWPTP inhibition primarily affects liver and adipose tissues, in contrast to PTP1B, which regulates insulin signaling in liver and skeletal muscle. These data suggest that PTP1B and LMWPTP have different tissue specificity in insulin signaling regulation ${ }^{[249]}$. Epidemiological studies have indicated that LMWPTP levels positively associate with serum glucose and triglyceride concentrations, and the highest LMWPTP levels have been recorded in diabetic and aged patients ${ }^{[250]}$. In addition, clinical studies have demonstrated that genotypes with elevated LMWPTP IF1 isoforms have the highest diabetic retinopathy incidence, a common but severe diabetic complication ${ }^{[251]}$. These findings indicate that LMWPTP is also a novel type 2 diabetes drug target.

\section{CDC25 in cancer}

The CDC25 phosphatases are dual-specificity phosphatases comprised of 3 members, CDC25A, CDC25B, and CDC25C, encoded by genes on 3 different chromosomes ${ }^{[252-255]}$. CDC25A, CDC25B, and CDC25C have 423 to 566 amino acids with a conserved C-terminal PTP catalytic domain and a nonconserved $\mathrm{N}$-terminal regulatory domain for various posttranslational modifications, including phosphorylation, ubiquitination, proline isomerization, and 14-3-3 sequestration ${ }^{[256]}$. The CDC25 family plays critical roles in cell cycle control by dephosphorylating negative regulatory residues of cyclindependent kinases (CDKs) (Figure 6B), which are important elements of cell cycle progression ${ }^{[257]}$. Specifically, CDC25A plays a significant role in the $\mathrm{G}_{1}-\mathrm{S}$ transition by activating the cyclin A and cyclin E-CDK2 complexes ${ }^{[258-260]}$; CDC25B partially activates the centrosomal cyclin B-CDK1 complex during the $\mathrm{G}_{2}$ to mitosis transition, and nuclear CDC25C further activates the complex during mitosis ${ }^{[261-263]}$.

Dysregulated cell cycle control is a hallmark of cancer cells to gain a growth advantage. Thus, the CDC25 family has gained much attention as potential cancer drug targets ${ }^{[256,264]}$. Studies have shown that CDC25 causes cell cycle deregulation and consequent cell genome instability, which contributes to cancer initiation and progression. For instance, CDC25A and CDC25B can transform normal mouse embryonic fibroblasts into oncogenic foci in soft agar and tumors in nude mice with oncogenic Ras or loss of RB1 ${ }^{[265]}$. CDC25B expression enhances mammary epithelial cell proliferation and induces precocious alveolar hyperplasia ${ }^{[266]}$, and further increases tumor onset susceptibility upon carcinogen exposure (9,10-dimethyl-1, 2-benzanthracene, DMBA) ${ }^{[267]}$. CDC25A, CDC25B, and CDC25C have been found to be overexpressed in a number of human cancers, including breast, colon, gastric, lung, colorectal, pancreatic, neuroblastoma, head and neck, and non Hodgkin's lymphoma ${ }^{[264]}$, and their overexpression occurs at all stages of tumorigenesis, suggesting that they may play critical roles throughout tumor development. Various small molecule CDC25 inhibitors have been developed and possess anticancer properties. For example, the IPSEN research laboratory developed BN82685 to inhibit CDC25A, B, C with $\mathrm{IC}_{50}$ values of 250,250 , and $170 \mathrm{nmol} / \mathrm{L}$, respectively ${ }^{[268]}$. This compound blocks proliferation across a large panel of human cells, as well as tumor growth in xenograft mice with the pancreas carcinoma cell line Mia PaCa- $2^{[268]}$. Therefore, the CDC25 family of phosphatases represent novel and attractive cancer targets.

\section{Strategies to modulate PTP activity}

There are several ways to modulate PTP activity, and the most popular strategy is to design active site directed and non-hydrolyzable pTyr mimetic-based small molecules. This technique has successfully produced potent inhibitors against several PTPs ${ }^{[7,25]}$. However, the major challenges of this strategy are specificity due to conserved PTP structure, and cell permeability due to the positively charged PTP active sites. The cell permeability and inhibitor specificity are important 
considerations in PTP-based drug discovery because PTP domains are cytosolic and many PTPs may function as tumor suppressors and should not be inadvertently targeted. The recent discovery of cell permeable pTyr mimetic salicylic acid-based inhibitors have achieved appreciable success in addressing these challenges ${ }^{[269]}$.

Targeting allosteric PTP1B sites is a good strategy in the development of high specificity and cell permeability inhibitors ${ }^{[270]}$. Allosteric inhibitors are not required to have multiple negative charges and therefore may possess more favorable pharmacological properties. However, it still seems difficult to improve their potency, as allosteric sites are not as welldefined as the active site.

Another strategy is to develop mechanism-based inhibitors, which inactivate the PTP catalytic cysteine residue through oxidation or other modifications. This strategy has been employed in quinone-based CDC25 inhibitors ${ }^{[11]}$. However, quinone compounds may induce reactive oxygen species, which may inactivate various redox-sensitive enzymes and cause in vivo toxicity ${ }^{[271,272]}$. Although they seemingly possess great activities against PTPs in vitro, they are not appealing for drug development. Irreversible and selective kinase inhibitor development has generated renewed interest in covalent enzyme inhibitors ${ }^{[273,274]}$. This can be achieved by building a Michael acceptor into a known competitive and specific inhibitor, which then forms a covalent bond with an adjacent cysteine residue. Thus, it will be interesting to employ a similar approach to develop irreversible and specific PTP inhibitors. Unlike quinone-based PTP inhibitors, these irreversible inhibitors would not target all redox-sensitive enzymes in cells.

In addition, ASOs against PTP1B and LMWPTP have been reported $^{[249,275,276]}$. Because they are $\sim 20$-mer oligonucleotides that target PTP mRNA, they are highly specific. PTP1B and LMWPTP ASOs have been reported to increase insulin sensitivity, reduce body glucose level, and control weight gain in animal studies and clinical trials, indicating their therapeutic potential. siRNAs may be an alternative approach in targeting PTPs through similar mechanisms. Nevertheless, challenges include low target delivery efficiency and safety of long-term consumption.

\section{Concluding remarks}

Protein-tyrosine phosphorylation dysregulation is a major cause of various human diseases, and great success has been achieved in PTK target drug discovery ${ }^{[3]}$. PTPs represent promising next generation drug targets for decades to come. For instance, PTP1B and LMWPTP are well-known negative regulators of the insulin signaling pathway and are excellent drug targets for type 2 diabetes and insulin resistance. SHP2, PRLs, LMWPTP, CDC25, CD45, FAP-1, and MKP-1 play positive roles in tumorigenesis by distinct mechanisms, and they can be targeted to combat a number of human cancers or to sensitize cancer chemotherapy or radiation therapy. LYP and CD45 are exciting drug targets for autoimmune diseases, such as type 1 diabetes, rheumatoid arthritis, and systemic lupus erythematosus. As a brain-restricted PTP, STEP is an emerging target for neurological disease and disorder treatment, such as Alzheimer's disease, Huntington's disease, schizophrenia, and alcohol abuse. In addition, MKP-1 may be relevant in depression and may be a novel target for this common and debilitating neurological illnesses.

Although there is growing recognition of PTPs as promising therapeutic targets, there are no commercialized PTP inhibitors despite extensive pharmaceutical industry efforts. The reasons for this lack of success in PTP-based drug discovery are both historical and technological. Historically, PTP research and development has run approximately 10 years behind PTK research because PTKs were discovered earlier and because PTPs have been erroneously viewed as exclusive negative regulators of hyperactive pathways in disease. Prior to the Human Genome Project, it was commonly believed that PTPs constituted a small group of 'housekeeping' enzymes with functions too broad and conserved to be selectively therapeutically inhibited. It is now known that there are actually more PTPs (107) than PTKs (90), and accordingly, many PTPs have unique and non-redundant functions in health and disease, making them attractive drug targets.

Unfortunately, PTPs present several key challenges to traditional drug development. The PTP active site is highly conserved, so it is not trivial to produce compounds that can selectively inhibit single PTPs. This is an issue common to most target families that act upon common substrate motifs (such as pTyr for PTPs or ATP for kinases) and has been overcome in the kinase field by high throughput screening and structure-based drug design. A more serious issue in PTPbased drug discovery is that the PTP active site is highly positively charged and contains a conserved catalytic cysteine residue. Thus, high-throughput screening of large compound collections usually leads to initial hits that are strongly negatively charged or contain oxidizing groups that irreversibly react with the catalytic cysteine. Heavily charged molecules do not readily cross cell membranes and cannot be made into drugs in their native form, and chemically-reactive compounds (eg, quinones) have poor safety and selectivity profiles, making them unappealing drug candidates. Despite these challenges, a new, focused, pragmatic approach to PTP inhibitor drug discovery and development is required. Recent studies using fragment-based and structure-guided approaches to target the PTP active site and adjacent less-conserved pockets demonstrate that it is feasible to obtain PTP inhibitors with high affinity, selectivity, and excellent in vivo efficacy in animal models of oncology, diabetes/obesity, autoimmunity, and tuberculosis ${ }^{[277]}$. Further work will advance the lead generation paradigm and create a 'PTP-based drug discovery platform' that will ultimately broadly impact drug development of tomorrow.

\section{Acknowledgements}

This work was supported in part by National Institutes of Health Grants CA69202 and CA126937. 


\section{References}

1 Sams-Dodd F. Target-based drug discovery: is something wrong? Drug Discov Today 2005; 2: 139-47.

2 Overington JP, Al-Lazikani B, Hopkins AL. Opinion-How many drug targets are there? Nat Rev Drug Discov 2006; 12: 993-6.

3 Cohen P, Alessi DR. Kinase drug discovery - what's next in the field? ACS Chem Biol 2013; 1: 96-104.

4 Hunter T. Protein-kinases and phosphatases - the yin and yang of protein-phosphorylation and signaling. Cell 1995; 2: 225-36.

5 Deng Y, Deng H, Zhu SL, Xu P, Shi ZY, Shan BL. Nature with Math Physics Yin Yang. J Math Med 1999; 1: 48-9.

6 Tonks NK, Neel BG. Combinatorial control of the specificity of protein tyrosine phosphatases. Curr Opin Cell Biol 2001; 2: 182-95.

7 Bialy L, Waldmann $\mathrm{H}$. Inhibitors of protein tyrosine phosphatases: next-generation drugs? Angew Chem Int Edit 2005; 25: 3814-39.

8 Tonks NK. Protein tyrosine phosphatases: from genes, to function, to disease. Nat Rev Mol Cell Biol 2006; 11: 833-46.

9 Julien SG, Dube N, Hardy S, Tremblay ML. Inside the human cancer tyrosine phosphatome. Nat Rev Cancer 2011; 1: 35-49.

10 Tonks NK. Protein tyrosine phosphatases - from housekeeping enzymes to master regulators of signal transduction. FEBS J 2013; 2: 346-78.

11 He R, Zhang ZY. Current status of PTP-based therapeutics. In: Neel BG, Tonks NK, editors. Protein tyrosine phosphatases in cancer. New York: Cancer Research at Springer; 2014. in press.

12 Alonso A, Sasin J, Bottini N, Friedberg I, Osterman A, Godzik A, et al. Protein tyrosine phosphatases in the human genome. Cell 2004; 6 : 699-711.

13 Li X, Oghi KA, Zhang J, Krones A, Bush KT, Glass CK, et al. Eya protein phosphatase activity regulates Six1-Dach-Eya transcriptional effects in mammalian organogenesis. Nature 2003; 6964: 247-54.

14 van Huijsduijnen RH, Bombrun A, Swinnen D. Selecting protein tyrosine phosphatases as drug targets. Drug Discov Today 2002; 19: 1013-9.

15 Tonks NK, Diltz CD, Fischer EH. Purification of the major proteintyrosine-phosphatases of human-placenta. J Biol Chem 1988; 14: 6722-30.

16 Zhang ZY, Lee SY. PTP1B inhibitors as potential therapeutics in the treatment of type 2 diabetes and obesity. Expert Opin Investig Drugs 2003; 2: 223-33.

17 Bandyopadhyay D, Kusari A, Kenner KA, Liu F, Chernoff J, Gustafson $\mathrm{TA}$, et al. Protein-tyrosine phosphatase $1 \mathrm{~B}$ complexes with the insulin receptor in vivo and is tyrosine-phosphorylated in the presence of insulin. J Biol Chem 1997; 3: 1639-45.

18 Goldstein BJ, Bittner-Kowalczyk A, White MF, Harbeck M. Tyrosine dephosphorylation and deactivation of insulin receptor substrate-1 by protein-tyrosine phosphatase $1 \mathrm{~B}$ - Possible facilitation by the formation of a ternary complex with the GRB2 adaptor protein. J Biol Chem 2000; 6: 4283-9.

19 Kaszubska W, Falls HD, Schaefer VG, Haasch D, Frost L, Hessler P, et al. Protein tyrosine phosphatase $1 \mathrm{~B}$ negatively regulates leptin signaling in a hypothalamic cell line. Mol Cell Endocrinol 2002; 1-2: 109-18.

20 Lund IK, Hansen JA, Andersen HS, Moller NPH, Billestrup N. Mechanism of protein tyrosine phosphatase 1B-mediated inhibition of leptin signalling. J Mol Endocrinol 2005; 2: 339-51.

21 Ahmad F, Li PM, Meyerovitch J, Goldstein BJ. Osmotic loading of neutralizing antibodies demonstrates a role for protein-tyrosinephosphatase $1 \mathrm{~b}$ in negative regulation of the insulin action pathway. J Biol Chem 1995; 35: 20503-8.

22 Zhang S, Zhang ZY. PTP1B as a drug target: recent developments in
PTP1B inhibitor discovery. Drug Discov Today 2007; 9-10: 373-81.

23 Elchebly M, Payette P, Michaliszyn E, Cromlish W, Collins S, Loy AL, et al. Increased insulin sensitivity and obesity resistance in mice lacking the protein tyrosine phosphatase-1B gene. Science 1999; 5407: 1544-8.

24 Haj FG, Zabolotny JM, Kim YB, Kahn BB, Neel BG. Liver-specific protein-tyrosine phosphatase 1B (PTP1B) re-expression alters glucose homeostasis of PTP1B ${ }^{-/-}$mice. J Biol Chem 2005; 15: 15038-46.

25 Combs AP. Recent advances in the discovery of competitive protein tyrosine phosphatase $1 \mathrm{~B}$ inhibitors for the treatment of diabetes, obesity, and cancer. J Med Chem 2010; 6: 2333-44.

26 He R, Zeng LF, He Y, Zhang ZY. Recent advances in PTP1B inhibitor development for the treatment of type-2 diabetes and obesity. In: Jones RM, editor. New therapeutic strategies for type 2 diabetes: small molecule approaches. London: Royal Society of Chemistry; 2012. p 142-76.

27 Lessard L, Stuible M, Tremblay ML. The two faces of PTP1B in cancer. Biochim Biophys Acta 2010; 1804: 613-9.

28 Bjorge JD, Pang A, Fujita DJ. Identification of protein-tyrosine phosphatase $1 \mathrm{~B}$ as the major tyrosine phosphatase activity capable of dephosphorylating and activating c-Src in several human breast cancer cell lines. J Biol Chem 2000; 52: 41439-46.

29 Dube N, Cheng A, Tremblay ML. The role of protein tyrosine phosphatase 1B in Ras signaling. Proc Natl Acad Sci U S A 2004; 7: 1834-9.

30 Wiener JR, Kerns BJ, Harvey EL, Conaway MR, Iglehart JD, Berchuck $\mathrm{A}$, et al. Overexpression of the protein tyrosine phosphatase PTP1B in human breast cancer: association with $\mathrm{p} 185 \mathrm{c}$-erbB-2 protein expression. J Natl Cancer Inst 1994; 5: 372-8.

31 Bentires-Alj M, Neel BG. Protein-tyrosine phosphatase 1B is required for HER2/Neu-induced breast cancer. Cancer Res 2007; 6: 2420-4.

32 Julien SG, Dube N, Read M, Penney J, Paquet M, Han YX, et al. Protein tyrosine phosphatase $1 \mathrm{~B}$ deficiency or inhibition delays ErbB2-induced mammary tumorigenesis and protects from lung metastasis. Nat Genet 2007; 3: 338-46.

33 Chen QT, Li Y, Li Z, Zhao Q, Fan LQ. Overexpression of PTP1B in human colorectal cancer and its association with tumor progression and prognosis. J Mol Histol 2014; 2: 153-9.

34 Freeman RM, Plutzky J, Neel BG. Identification of a human src homology 2-containing protein-tyrosine-phosphatase-a putative homolog of drosophila corkscrew. Proc Natl Acad Sci U S A 1992; 23: 11239-43.

35 Neel BG, Gu HH, Pao L. The 'Shp'ing news: SH2 domain-containing tyrosine phosphatases in cell signaling. Trends Biochem Sci 2003; 6: 284-93.

36 Hof P, Pluskey S, Dhe-Paganon S, Eck MJ, Shoelson SE. Crystal structure of the tyrosine phosphatase SHP-2. Cell 1998; 4: 441-50.

37 Klinghoffer RA, Kazlauskas A. Identification of a putative syp substrate, the pdgf-beta receptor. J Biol Chem 1995; 38: 22208-17.

38 Ren Y, Meng SS, Mei L, Zhao ZJ, Jove R, Wu J. Roles of Gab1 and SHP2 in paxillin tyrosine dephosphorylation and Src activation in response to epidermal growth factor. J Biol Chem 2004; 9: 8497 505.

39 Hanafusa H, Torii S, Yasunaga T, Matsumoto K, Nishida E. Shp2, an $\mathrm{SH} 2$-containing protein-tyrosine phosphatase, positively regulates receptor tyrosine kinase signaling by dephosphorylating and inactivating the inhibitor sprouty. J Biol Chem 2004; 22: 22992-5.

40 Jarvis LA, Toering SJ, Simon MA, Krasnow MA, Smith-Bolton RK. Sprouty proteins are in vivo targets of Corkscrew/SHP-2 tyrosine phosphatases. Development 2006; 6: 1133-42. 
41 Li W, Nishimura R, Kashishian A, Batzer AG, Kim WJH, Cooper JA, et al. A new function for a phosphotyrosine phosphatase - linking grb2sos to a receptor tyrosine kinase. Mol Cell Biol 1994; 1: 509-17.

42 Zhang SQ, Tsiaras WG, Araki T, Wen GY, Minichiello L, Klein R, et al. Receptor-specific regulation of phosphatidylinositol 3'-kinase activation by the protein tyrosine phosphatase Shp2. Mol Cell Biol 2002; 12: 4062-72.

43 Mattoon DR, Lamothe B, Lax I, Schlessinger J. The docking protein Gab1 is the primary mediator of EGF-stimulated activation of the PI3K/Akt cell survival pathway. BMC Biol 2004; 2: 24.

44 Chan G, Kalaitzidis D, Neel BG. The tyrosine phosphatase Shp2 (PTPN11) in cancer. Cancer Metastasis Rev 2008; 2: 179-92.

45 Chan RJ, Feng GS. PTPN11 is the first identified proto-oncogene that encodes a tyrosine phosphatase. Blood 2007; 3: 862-7.

46 Miyamoto D, Miyamoto M, Takahashi A, Yomogita Y, Higashi H, Kondo S, et al. Isolation of a distinct class of gain-of-function SHP2 mutants with oncogenic RAS-like transforming activity from solid tumors. Oncogene 2008; 25: 3508-15.

47 Araki T, Mohi MG, Ismat FA, Bronson RT, Williams IR, Kutok JL, et al. Mouse model of Noonan syndrome reveals cell type- and gene dosage-dependent effects of Ptpn11 mutation. Nat Med 2004; 8: 849-57.

48 Chan G, Kalaitzidis D, Usenko T, Kutok JL, Yang WT, Mohi MG, et al. Leukemogenic Ptpn11 causes fatal myeloproliferative disorder via cell-autonomous effects on multiple stages of hematopoiesis. Blood 2009; 18: 4414-24.

49 Emanuel PD, Shannon KM, Castleberry RP. Juvenile myelomonocytic leukemia: molecular understanding and prospects for therapy. Mol Med Today 1996; 11: 468-75.

50 Chan RJ, Leedy MB, Munugalavadla V, Voorhorst CS, Li YJ, Yu MG, et al. Human somatic PTPN11 mutations induce hematopoietic-cell hypersensitivity to granulocyte-macrophage colony-stimulating factor. Blood 2005; 9: 3737-42.

51 Yang ZY, Li YP, Yin FQ, Chan RJ. Activating PTPN11 mutants promote hematopoietic progenitor cell-cycle progression and survival. Exp Hematol 2008; 10: 1285-96.

52 Zhang X, He YT, Liu SJ, Yu ZH, Jiang ZX, Yang ZY, et al. Salicylic acid based small molecule inhibitor for the oncogenic Src homology-2 domain containing protein tyrosine phosphatase-2 (SHP2). J Med Chem 2010; 6: 2482-93.

53 Liu W, Yu B, Xu G, Xu WR, Loh ML, Tang LD, et al. Identification of cryptotanshinone as an inhibitor of oncogenic protein tyrosine phosphatase SHP2 (PTPN11). J Med Chem 2013; 18: 7212-21.

54 Yu B, Liu W, Yu WM, Loh ML, Alter S, Guvench O, et al. Targeting protein tyrosine phosphatase SHP2 for the treatment of PTPN11associated malignancies. Mol Cancer Ther 2013; 9: 1738-48.

55 Mali RS, Ma PL, Zeng LF, Martin H, Ramdas B, He YT, et al. Role of SHP2 phosphatase in KIT-induced transformation: identification of SHP2 as a druggable target in diseases involving oncogenic KIT. Blood 2012; 13: 2669-78.

56 Aceto N, Sausgruber N, Brinkhaus H, Gaidatzis D, Martiny-Baron G, Mazzarol G, et al. Tyrosine phosphatase SHP2 promotes breast cancer progression and maintains tumor-initiating cells via activation of key transcription factors and a positive feedback signaling loop. Nat Med 2012; 4: 529-37.

57 Xu J, Zeng LF, Shen WH, Turchi JJ, Zhang ZY. Targeting SHP2 for EGFR inhibitor resistant non-small cell lung carcinoma. Biochem Biophys Res Commun 2013; 4: 586-90.

58 Cohen S, Dadi H, Shaoul E, Sharfe N, Roifman CM. Cloning and characterization of a lymphoid-specific, inducible human protein tyrosine phosphatase, Lyp. Blood 1999; 6: 2013-24.
59 Mustelin T, Vang T, Bottini N. Protein tyrosine phosphatases and the immune response. Nat Rev Immunol 2005; 1: 43-57.

60 Vang T, Miletic AV, Arimura Y, Tautz L, Rickert RC, Mustelin T. Protein tyrosine phosphatases in autoimmunity. Annu Rev Immunol Palo Alto: Annual Reviews; 2008. p 29-55.

61 Fousteri G, Liossis SNC, Battaglia M. Roles of the protein tyrosine phosphatase PTPN22 in immunity and autoimmunity. Clin Immunol 2013; 3: 556-65.

62 Cloutier JF, Veillette A. Cooperative inhibition of T-cell antigen receptor signaling by a complex between a kinase and a phosphatase. J Exp Med 1999; 1: 111-21.

63 Gjorloff-Wingren A, Saxena M, Williams S, Hammi D, Mustelin T. Characterization of TCR-induced receptor-proximal signaling events negatively regulated by the protein tyrosine phosphatase PEP. Eur J Immunol 1999; 12: 3845-54.

64 Cloutier JF, Veillette A. Association of inhibitory tyrosine protein kinase p50csk with protein tyrosine phosphatase PEP in T cells and other hemopoietic cells. EMBO J 1996; 18: 4909-18.

65 Gregorieff A, Cloutier JF, Veillette A. Sequence requirements for association of protein-tyrosine phosphatase PEP with the Src homology 3 domain of inhibitory tyrosine protein kinase p50(csk). J Biol Chem 1998; 21: 13217-22.

66 Ghose R, Shekhtman A, Goger MJ, Ji H, Cowburn D. A novel, specific interaction involving the Csk SH3 domain and its natural ligand. Nat Struct Biol 2001; 11: 998-1004.

67 Hasegawa K, Martin F, Huang GM, Tumas D, DiehI L, Chan AC. PEST domain-enriched tyrosine phosphatase (PEP) regulation of effector/ memory T cells. Science 2004; 5658: 685-9.

68 Bottini N, Musumeci L, Alonso A, Rahmouni S, Nika K, Rostamkhani $\mathrm{M}$, et al. A functional variant of lymphoid tyrosine phosphatase is associated with type I diabetes. Nat Genet 2004; 4: 337-8.

69 Pei Z, Chen X, Sun C, Du H, Wei H, Song W, et al. A novel single nucleotide polymorphism in the protein tyrosine phosphatase N22 gene (PTPN22) is associated with type 1 diabetes in a Chinese population. Diabet Med 2014; 2: 219-26.

70 Begovich AB, Carlton VEH, Honigberg LA, Schrodi SJ, Chokkalingam $\mathrm{AP}$, Alexander $\mathrm{HC}$, et al. A missense single-nucleotide polymorphism in a gene encoding a protein tyrosine phosphatase (PTPN22) is associated with rheumatoid arthritis. Am J Hum Genet 2004; 2: 330-7.

71 Lee AT, Li W, Liew A, Bombardier C, Weisman M, Massarotti EM, et al. The PTPN22 R620W polymorphism associates with RF positive rheumatoid arthritis in a dose-dependent manner but not with HLASE status. Genes Immun 2005; 2: 129-33.

72 Smyth D, Cooper JD, Collins JE, Heward JM, Franklyn JA, Howson JMM, et al. Replication of an association between the lymphoid tyrosine phosphatase locus (LYP/PTPN22) with type 1 diabetes, and evidence for its role as a general autoimmunity locus. Diabetes 2004; 11: 3020-3.

73 Velaga MR, Wilson V, Jennings CE, Owen CJ, Herington S, Donaldson PT, et al. The codon 620 tryptophan allele of the lymphoid tyrosine phosphatase (LYP) gene is a major determinant of Graves' disease. J Clin Endocrinol Metab 2004; 11: 5862-5.

74 Vandiedonck C, Capdevielle C, Giraud M, Krumeich S, Jais JP, Eymard $B$, et al. Association of the PTPN22*R620W polymorphism with autoimmune myasthenia gravis. Ann Neurol 2006; 2: 404-7.

75 Kyogoku C, Langefeld CD, Ortmann WA, Lee A, Selby S, Carlton VEH, et al. Genetic association of the R620W polymorphism of protein tyrosine phosphatase PTPN22 with human SLE. Am J Hum Genet 2004; 3: 504-7.

76 Vang T, Congia M, Macis MD, Musumeci L, Orru V, Zavattari P, et al. 
Autoimmune-associated lymphoid tyrosine phosphatase is a gain-offunction variant. Nat Genet 2005; 12: 1317-9.

77 Vang T, Liu WH, Delacroix L, Wu SD, Vasile S, Dahl R, et al. LYP inhibits T-cell activation when dissociated from CSK. Nat Chem Biol 2012; 5: 437-46.

78 Zhang JY, Zahir N, Jiang QH, Miliotis H, Heyraud S, Meng XW, et al. The autoimmune disease-associated PTPN22 variant promotes calpain-mediated Lyp/Pep degradation associated with lymphocyte and dendritic cell hyperresponsiveness. Nat Genet 2011; 9: 902U122.

79 Dai XZ, James RG, Habib T, Singh S, Jackson S, Khim S, et al. A disease-associated PTPN22 variant promotes systemic autoimmunity in murine models. J Clin Invest 2013; 5: 2024-36.

80 Stanford SM, Krishnamurthy D, Falk MD, Messina R, Debnath B, Li $\mathrm{S}$, et al. Discovery of a novel series of inhibitors of lymphoid tyrosine phosphatase with activity in human T cells. J Med Chem 2011; 6 : 1640-54.

81 Krishnamurthy D, Karver MR, Fiorillo E, Orru V, Stanford SM, Bottini N, et al. Gold(I)-mediated inhibition of protein tyrosine phosphatases: A detailed in vitro and cellular study. J Med Chem 2008; 15: 4790-5.

82 He YT, Liu SJ, Menon A, Stanford S, Oppong E, Gunawan AM, et al. A potent and selective small-molecule inhibitor for the lymphoidspecific tyrosine phosphatase (LYP), a target associated with autoimmune diseases. J Med Chem 2013; 12: 4990-5008.

83 Andersson LC, Karhi KK, Gahmberg CG, Rodt H. Molecular identification of $\mathrm{T}$ cell-specific antigens on human T lymphocytes and thymocytes. Eur J Immunol 1980; 5: 359-62.

84 Omary MB, Trowbridge IS, Battifora HA. Human homologue of murine T200 glycoprotein. J Exp Med 1980; 4: 842-52.

85 Hermiston ML, Xu Z, Weiss A. CD45: A critical regulator of signaling thresholds in immune cells. Annu Rev Immunol 2003; 21: 107-37.

86 Desai DM, Sap J, Silvennoinen 0, Schlessinger J, Weiss A. The catalytic activity of the cd45 membrane-proximal phosphatase domain is required for TCR signaling and regulation. EMBO J 1994; 17: 4002-10.

87 Trowbridge IS, Thomas ML. CD45 - an emerging role as a proteintyrosine-phosphatase required for lymphocyte-activation and development. Annu Rev Immunol 1994; 12: 85-116.

88 Thomas ML. The leukocyte common antigen family. Annu Rev Immunol 1989; 7: 339-69.

89 Ashwell JD, D'Oro U. CD45 and Src-family kinases: and now for something completely different. Immunol Today 1999; 9: 412-6.

90 Thomas ML, Brown EJ. Positive and negative regulation of Src-family membrane kinases by CD45. Immunol Today 1999; 9: 406-11.

91 Alexander DR. The CD45 tyrosine phosphatase: a positive and negative regulator of immune cell function. Semin Immunol 2000; 4: 349-59.

92 McFarland EDC, Hurley TR, Pingel JT, Sefton BM, Shaw A, Thomas ML. Correlation between src family member regulation by the protein-tyrosine-phosphatase cd45 and transmembrane signaling through the T-cell receptor. Proc Natl Acad Sci U S A 1993; 4: 14026.

93 Sieh M, Bolen JB, Weiss A. CD45 specifically modulates binding of Lck to a phosphopeptide encompassing the negative regulatory tyrosine of LCK. EMBO J 1993; 1: 315-21.

94 Stone JD, Conroy LA, Byth KF, Hederer RA, Howlett S, Takemoto Y, et al. Aberrant TCR-mediated signaling in CD45-null thymocytes involves dysfunctional regulation of Lck, Fyn, TCR-zeta and ZAP-70. J Immunol 1997; 12: 5773-82.

95 Seavitt JR, White LS, Murphy KM, Loh DY, Perlmutter RM, Thomas ML. Expression of the p56(Ick) Y505F mutation in CD45-deficient mice rescues thymocyte development. Mol Cell Biol 1999; 6: 42008.

96 Burns CM, Sakaguchi K, Appella E, Ashwell JD. CD45 regulation of tyrosine phosphorylation and enzyme-activity of src family kinases. J Biol Chem 1994; 18: 13594-600.

97 D'Oro U, Ashwell JD. Cutting edge: The CD45 tyrosine phosphatase is an inhibitor of Lck activity in thymocytes. J Immunol 1999; 4: 1879-83.

98 McNeill L, Salmond RJ, Cooper JC, Carret CK, Cassady-Cain RL, Roche-Molina $\mathrm{M}$, et al. The differential regulation of Ick kinase phosphorylation sites by CD45 is critical for T cell receptor signaling responses. Immunity 2007; 3: 425-37.

99 Katagiri T, Ogimoto M, Hasegawa K, Mizuno K, Yakura H. Selective regulation of lyn tyrosine kinase by CD45 in immature B-cells. J Biol Chem 1995; 47: 27987-90.

100 Yanagi S, Sugawara H, Kurosaki M, Sabe H, Yamamura H, Kurosaki T. CD45 modulates phosphorylation of both autophosphorylation and negative regulatory tyrosines of Lyn in B cells. J Biol Chem 1996; 48: 30487-92.

101 Katagiri T, Ogimoto M, Hasegawa K, Arimura Y, Mitomo K, Okada M, et al. CD45 negatively regulates Lyn activity by dephosphorylating both positive and negative regulatory tyrosine residues in immature B cells. J Immunol 1999; 3: 1321-6.

102 Irie-Sasaki J, Sasaki T, Matsumoto W, Opavsky A, Cheng M, Welstead G, et al. CD45 is a JAK phosphatase and negatively regulates cytokine receptor signalling. Nature 2001; 6818: 349-54.

103 Roach T, Slater S, Koval M, White L, McFarland EC, Okumura M, et al. CD45 regulates Src family member kinase activity associated with macrophage integrin-mediated adhesion. Curr Biol 1997; 6: 408-17.

104 Trop S, Charron J, Arguin C, Hugo P. Thymic selection generates $T$ cells expressing self-reactive TCRs in the absence of CD45. J Immunol 2000; 6: 3073-9.

105 Tchilian EZ, Beverley PCL. Altered CD45 expression and disease. Trends Immunol 2006; 3: 146-53.

106 Jacobsen M, Schweer D, Ziegler A, Gaber R, Schock S, Schwinzer R, et al. A point mutation in PTPRC is associated with the development of multiple sclerosis. Nat Genet 2000; 4: 495-9.

107 Ballerini C, Rosati E, Salvetti M, Ristori G, Cannoni S, Biagioli T, et al. Protein tyrosine phosphatase receptor-type $\mathrm{C}$ exon 4 gene mutation distribution in an Italian multiple sclerosis population. Neurosci Lett 2002; 3: 325-7.

108 Vyshkina T, Leist TP, Shugart YY, Kalman B. CD45 (PTPRC) as a candidate gene in multiple sclerosis. Mult Scler 2004; 6: 614-7.

109 Tchilian EZ, Wallace DL, Dawes R, Imami N, Burton C, Gotch F, et al. A point mutation in CD45 may be associated with an increased risk of HIV-1 infection. AIDS 2001; 14: 1892-4.

110 Vogel A, Strassburg CP, Manns MP. 77 C/G mutation in the tyrosine phosphatase CD45 gene and autoimmune hepatitis: evidence for a genetic link. Genes Immun 2003; 1: 79-81.

111 Schwinzer R, Witte T, Hundrieser J, Ehlers S, Momot T, Hunzelmann $\mathrm{N}$, et al. Enhanced frequency of a PTPRC (CD45) exon A mutation $(77 C \rightarrow G)$ in systemic sclerosis. Genes Immun 2003; 2: 168-9.

112 Lynch KW, Weiss A. A CD45 polymorphism associated with multiple sclerosis disrupts an exonic splicing silencer. J Biol Chem 2001; 26 : 24341-7.

113 Jacobsen M, Hoffmann S, Cepok S, Stei S, Ziegler A, Sommer N, et al. A novel mutation in PTPRC interferes with splicing and alters the structure of the human CD45 molecule. Immunogenetics 2002; 3: 158-63.

114 Stanton T, Boxall S, Hirai K, Dawes R, Tonks S, Yasui T, et al. A highfrequency polymorphism in exon 6 of the CD45 tyrosine phosphatase 
gene (PTPRC) resulting in altered isoform expression. Proc Natl Acad Sci U S A 2003; 10: 5997-6002.

115 Boxall S, Stanton T, Hirai K, Ward V, Yasui T, Tahara H, et al. Disease associations and altered immune function in CD45 138G variant carriers. Hum Mol Genet 2004; 20: 2377-84.

116 Majeti R, Xu Z, Parslow TG, Olson JL, Daikh DI, Killeen N, et al. An inactivating point mutation in the inhibitory wedge of CD45 causes lymphoproliferation and autoimmunity. Cell 2000; 7: 1059-70.

117 Nemecek ER, Matthews DC. Antibody-based therapy of human leukemia. Curr Opin Hematol 2002; 4: 316-21.

118 Matthews DC, Appelbaum FR, Eary JF, Fisher DR, Durack LD, Hui TE, et al. Phase I study of ${ }^{131}$ I-anti-CD 45 antibody plus cyclophosphamide and total body irradiation for advanced acute leukemia and myelodysplastic syndrome. Blood 1999; 4: 1237-47.

119 Orozco JJ, Back T, Kenoyer A, Balkin ER, Hamlin DK, Wilbur DS, et al. Anti-CD45 radioimmunotherapy using At-211 with bone marrow transplantation prolongs survival in a disseminated murine leukemia model. Blood 2013; 18: 3759-67.

120 Pagel JM, Kenoyer AL, Back T, Hamlin DK, Wilbur DS, Fisher DR, et al. Anti-CD45 pretargeted radioimmunotherapy using bismuth-213: high rates of complete remission and long-term survival in a mouse myeloid leukemia xenograft model. Blood 2011; 3: 703-11.

121 Banville D, Ahmad S, Stocco R, Shen SH. A novel protein-tyrosine phosphatase with homology to both the cytoskeletal proteins of the band 4.1 family and junction-associated guanylate kinases. J Biol Chem 1994; 35: 22320-7.

122 Maekawa K, Imagawa N, Nagamatsu M, Harada S. Molecular-cloning of a novel protein-tyrosine-phosphatase containing a membranebinding domain and GLGF repeats. FEBS Lett 1994; 2: 200-6.

123 Saras J, Claessonwelsh L, Heldin CH, Gonez LJ. Cloning and characterization of ptpl1, a protein-tyrosine-phosphatase with similarities to cytoskeletal-associated proteins. J Biol Chem 1994; 39: 24082-9.

124 Bompard G, Martin M, Roy C, Vignon F, Freiss G. Membrane targeting of protein tyrosine phosphatase PTPL1 through its FERM domain via binding to phosphatidylinositol 4,5-biphosphate. J Cell Sci 2003; 12 : 2519-30.

125 Abaan OD, Toretsky JA. PTPL1: a large phosphatase with a split personality. Cancer Metastasis Rev 2008; 2: 205-14.

126 Andersen JN, Mortensen OH, Peters GH, Drake PG, Iversen LF, Olsen $\mathrm{OH}$, et al. Structural and evolutionary relationships among protein tyrosine phosphatase domains. Mol Cell Biol 2001; 21: 7117-36.

127 Villa F, Deak M, Bloomberg GB, Alessi DR, van Aalten DMF. Crystal structure of the PTPL1/FAP-1 human tyrosine phosphatase mutated in colorectal cancer - Evidence for a second phosphotyrosine substrate recognition pocket. J Biol Chem 2005; 9: 8180-7.

128 Sato T, Irie S, Kitada S, Reed JC. FAP-1-a protein-tyrosinephosphatase that associates with FAS. Science 1995; 5209: 411-5.

129 Saras J, Engstrom U, Gonez LJ, Heldin CH. Characterization of the interactions between PDZ domains of the protein-tyrosine phosphatase PTPL1 and the carboxyl-terminal tail of Fas. J Biol Chem 1997; 34: 20979-81.

130 Yanagisawa J, Takahashi M, Kanki H, Yano-Yanagisawa H, Tazunoki $\mathrm{T}$, Sawa E, et al. The molecular interaction of Fas and FAP-1 - A tripeptide blocker of human Fas interaction with FAP-1 promotes Fasinduced apoptosis. J Biol Chem 1997; 13: 8539-45.

131 Ivanov VN, Bergami PL, Maulit G, Sato TA, Sassoon D, Ronai Z. FAP1 association with Fas (Apo-1) inhibits Fas expression on the cell surface. Mol Cell Biol 2003; 10: 3623-35.

132 Irie S, Hachiya T, Rabizadeh S, Maruyama W, Mukai J, Li Y, et al. Functional interaction of Fas-associated phosphatase-1 (FAP-1) with $\mathrm{p} 75$ (NTR) and their effect on NF-kappa B activation. FEBS Lett 1999; 2: 191-8.

133 Erdmann KS, Kuhlmann J, Lessmann V, Herrmann L, Eulenburg $\mathrm{V}$, Muller $\mathrm{O}$, et al. The adenomatous polyposis coli-protein (APC) interacts with the protein tyrosine phosphatase PTP-BL via an alternatively spliced PDZ domain. Oncogene 2000; 34: 3894-901.

134 Maekawa K, Imagawa N, Naito A, Harada S, Yoshie O, Takagi S. Association of protein-tyrosine phosphatase PTP-BAS with the transcription-factor-inhibitory protein I kappa-B alpha through interaction between the PDZ1 domain and ankyrin repeats. Biochem J 1999; 337: 179-84.

135 Nakai Y, Irie S, Sato TA. Identification of I kappa B alpha as a substrate of Fas-associated phosphatase-1. Eur J Biochem 2000; 24: 7170-5.

136 Dromard M, Bompard G, Glondu-Lassis M, Puech C, Chalbos D, Freiss G. The putative tumor suppressor gene PTPN13/PTPL1 induces apoptosis through insulin receptor substrate-1 dephosphorylation. Cancer Res 2007; 14: 6806-13.

137 Zhu JH, Chen R, Yi W, Cantin GT, Fearns C, Yang Y, et al. Protein tyrosine phosphatase PTPN13 negatively regulates Her2/ErbB2 malignant signaling. Oncogene 2008; 18: 2525-31.

138 Nakahira M, Tanaka T, Robson BE, Mizgerd JP, Grusby MJ. Regulation of signal transducer and activator of transcription signaling by the tyrosine phosphatase PTP-BL. Immunity 2007; 2: 163-76.

139 Wansink DG, Peters W, Schaafsma I, Sutmuller RPM, Oerlemans F, Adema GJ, et al. Mild impairment of motor nerve repair in mice lacking PTP-BL tyrosine phosphatase activity. Physiol Genomics 2004; 1: 50-60.

140 Lorber B, Hendriks W, Van der Zee C, Berry M, Logan A. Effects of LAR and PTP-BL phosphatase deficiency on adult mouse retinal cells activated by lens injury. Eur J Neurosci 2005; 9: 2375-83.

141 Ungefroren H, Voss M, Jansen M, Roeder C, Henne-Bruns D, Kremer $B$, et al. Human pancreatic adenocarcinomas express Fas and Fas ligand yet are resistant to Fas-mediated apoptosis. Cancer Res 1998; 8: 1741-9.

142 Ungefroren H, Kruse ML, Trauzold A, Roeschmann S, Roeder C, Arlt A, et al. FAP-1 in pancreatic cancer cells: functional and mechanistic studies on its inhibitory role in CD95-mediated apoptosis. J Cell Sci 2001; 15: 2735-46.

143 Meinhold-Heerlein I, Stenner-Liewen F, Liewen H, Kitada S, Krajewska $\mathrm{M}, \mathrm{Krajewski} \mathrm{S}$, et al. Expression and potential role of Fas-associated phosphatase-1 in ovarian cancer. Am J Pathol 2001; 4: 1335-44.

144 Yao H, Song E, Chen J, Hamar P. Expression of FAP-1 by human colon adenocarcinoma: implication for resistance against Fas-mediated apoptosis in cancer. Br J Cancer 2004; 9: 1718-25.

145 Wieckowski E, Atarashi Y, Stanson J, Sato TA, Whiteside TL. FAP-1mediated activation of NF-kappa B induces resistance of head and neck cancer to Fas-induced apoptosis. J Cell Biochem 2007; 1: 16-28.

146 Lee SH, Shin MS, Lee JY, Park WS, Kim SY, Jang JJ, et al. In vivo expression of soluble Fas and Fap-1: Possible mechanisms of Fas resistance in human hepatoblastomas. J Pathol 1999; 2: 207-12.

147 Lee SH, Shin MS, Lee HS, Bae JH, Lee HK, Kim HS, et al. Expression of Fas and Fas-related molecules in human hepatocellular carcinoma. Hum Pathol 2001; 3: 250-6.

148 Uren A, Toretsky JA. Ewing's sarcoma oncoprotein EWS-FLI1: the perfect target without a therapeutic agent. Future Oncol 2005; 4: 521-8.

149 Abaan OD, Levenson A, Khan O, Furth PA, Uren A, Toretsky JA. PTPL1 is a direct transcriptional target of EWS-FLI1 and modulates Ewing's sarcoma tumorigenesis. Oncogene 2005; 16: 2715-22. 
150 Khan J, Wei JS, Ringner M, Saal LH, Ladanyi M, Westermann F, et al. Classification and diagnostic prediction of cancers using gene expression profiling and artificial neural networks. Nat Med 2001; 6: 673-9.

151 Lessnick SL, Dacwag CS, Golub TR. The Ewing's sarcoma oncoprotein EWS/FLI induces a p53-dependent growth arrest in primary human fibroblasts. Cancer Cell 2002; 4: 393-401.

152 Baer C, Nees M, Breit S, Selle B, Kulozik AE, Schaefer KL, et al. Profiling and functional annotation of MRNA gene expression in pediatric rhabdomyosarcoma and Ewing's sarcoma. Int J Cancer 2004; 5: 687-94.

153 Xiao ZY, Wu W, Eagleton N, Chen HQ, Shao J, Teng H, et al. Silencing Fas-associated phosphatase 1 expression enhances efficiency of chemotherapy for colon carcinoma with oxaliplatin. World J Gastroenterol 2010; 1: 112-8.

154 Savagner P. Leaving the neighborhood: molecular mechanisms involved during epithelial-mesenchymal transition. Bioessays 2001; 10: 912-23.

155 Gregory PA, Bert AG, Paterson EL, Barry SC, Tsykin A, Farshid G, et al. The mir-200 family and mir-205 regulate epithelial to mesenchymal transition by targeting ZEB1 and SIP1. Nat Cell Biol 2008; 5: 593601.

156 Peter ME. Let-7 and miR-200 microRNAs Guardians against pluripotency and cancer progression. Cell Cycle 2009; 6: 843-52.

157 Schickel R, Park SM, Murmann AE, Peter ME. mir-200c regulates induction of apoptosis through CD95 by targeting FAP-1. Mol Cell 2010; 6: 908-15.

158 Ying J, Li H, Cui Y, Wong AHY, Langford C, Tao Q. Epigenetic disruption of two proapoptotic genes MAPK10/JNK3 and PTPN13/FAP-1 in multiple lymphomas and carcinomas through hypermethylation of a common bidirectional promoter. Leukemia 2006; 6: 1173-5.

159 Yeh SH, Wu DC, Tsai CY, Kuo TJ, Yu WC, Chang YS, et al. Genetic characterization of Fas-associated phosphatase-1 as a putative tumor suppressor gene on chromosome $4 q 21.3$ in hepatocellular carcinoma. Clin Cancer Res 2006; 4: 1097-108.

160 Wang ZH, Shen D, Parsons DW, Bardelli A, Sager J, Szabo S, et al. Mutational analysis of the tyrosine phosphatome in colorectal cancers. Science 2004; 5674: 1164-6.

161 Lombroso PJ, Murdoch G, Lerner M. Molecular characterization of a protein-tyrosine-phosphatase enriched in striatum. Proc Natl Acad Sci U S A 1991; 16: 7242-6.

162 Lombroso PJ, Naegele JR, Sharma E, Lerner M. A protein-tyrosinephosphatase expressed within dopaminoceptive neurons of the basal ganglia and related structures. J Neurosci 1993; 7: 3064-74.

163 Bult A, Zhao F, Dirkx R, Raghunathan A, Solimena M, Lombroso PJ. STEP: A family of brain-enriched PTPs. Alternative splicing produces transmembrane, cytosolic and truncated isoforms. Eur J Cell Biol 1997; 4: 337-44.

164 Venkitaramani DV, Paul S, Zhang YF, Kurup P, Ding L, Tressler L, et al. Knockout of striatal enriched protein tyrosine phosphatase in mice results in increased ERK1/2 phosphorylation. Synapse 2009; 1 : 69-81.

165 Francis DM, Kumar GS, Koveal D, Tortajada A, Page R, Peti W. The differential regulation of $\mathrm{p} 38$ alpha by the neuronal kinase interaction motif protein tyrosine phosphatases, a detailed molecular study. Structure 2013; 9: 1612-23.

166 Sweatt JD. Mitogen-activated protein kinases in synaptic plasticity and memory. Curr Opin Neurobiol 2004; 3: 311-7.

167 Cuenda A, Rousseau S. P38 MAP-Kinases pathway regulation, function and role in human diseases. Biochim Biophys Acta-Mol Cell Res 2007; 8: 1358-75.
168 Borders AS, de Almeida L, Van Eldik $\sqcup$, Watterson DM. The p38alpha mitogen-activated protein kinase as a central nervous system drug discovery target. BMC Neurosci 2008; 9 Suppl 2: S12.

169 Zhang Y, Venkitaramani DV, Gladding CM, Zhang YF, Kurup P, Molnar $\mathrm{E}$, et al. The tyrosine phosphatase STEP mediates AMPA receptor endocytosis after metabotropic glutamate receptor stimulation. J Neurosci 2008; 42: 10561-6.

170 Nguyen TH, Liu J, Lombroso PJ. Striatal enriched phosphatase 61 dephosphorylates Fyn at phosphotyrosine 420. J Biol Chem 2002; 27: 24274-9.

171 Nakazawa T, Komai S, Tezuka T, Hisatsune C, Umemori H, Semba $\mathrm{K}$, et al. Characterization of Fyn-mediated tyrosine phosphorylation sites on GluR epsilon 2 (NR2B) subunit of the $\mathrm{N}$-methyl-D-aspartate receptor. J Biol Chem 2001; 1: 693-9.

172 Snyder EM, Nong Y, Almeida CG, Paul S, Moran T, Choi EY, et al. Regulation of NMDA receptor trafficking by amyloid-beta. Nat Neurosci 2005; 8: 1051-8.

173 Kurup P, Zhang Y, Xu J, Venkitaramani DV, Haroutunian V, Greengard $\mathrm{P}$, et al. Abeta-mediated NMDA receptor endocytosis in Alzheimer's disease involves ubiquitination of the tyrosine phosphatase STEP61. J Neurosci 2010; 17: 5948-57.

174 Goebel-Goody SM, Baum M, Paspalas CD, Fernandez SM, Carty NC, Kurup P, et al. Therapeutic implications for striatal-enriched protein tyrosine phosphatase (STEP) in neuropsychiatric disorders. Pharmacol Rev 2012; 1: 65-87.

175 Kurup P, Zhang YF, Venkitaramani DV, Xu JA, Lombroso PJ. The role of STEP in Alzheimer's disease. Channels 2010; 5: 347-50.

176 Carty NC, Xu J, Kurup P, Brouillette J, Goebel-Goody SM, Austin DR, et al. The tyrosine phosphatase STEP: implications in schizophrenia and the molecular mechanism underlying antipsychotic medications. Transl Psychiatr 2012; 2: e137.

177 Hicklin TR, Wu PH, Radcliffe RA, Freund RK, Goebel-Goody SM, Correa PR, et al. Alcohol inhibition of the NMDA receptor function, long-term potentiation, and fear learning requires striatal-enriched protein tyrosine phosphatase. Proc Natl Acad Sci U S A 2011; 16 : 6650-5.

178 Theodosiou A, Ashworth A. MAP kinase phosphatases. Genome Biol 2002; 3: REVIEWS3009.

179 Charles $\mathrm{CH}$, Abler AS, Lau LF. cDNA sequence of a growth factorinducible immediate early gene and characterization of its encoded protein. Oncogene 1992; 1: 187-90.

180 Sun H, Charles CH, Lau LF, Tonks NK. MKP-1 (3CH134), an immediate early gene product, is a dual specificity phosphatase that dephosphorylates map kinase in vivo. Cell 1993; 3: 487-93.

$181 \mathrm{Wu} \mathrm{JJ}$, Zhang L, Bennett AM. The noncatalytic amino terminus of mitogen-activated protein kinase phosphatase 1 directs nuclear targeting and serum response element transcriptional regulation. Mol Cell Biol 2005; 11: 4792-803.

182 Guan KL, Butch E. Isolation and characterization of a novel dual specific phosphatase, hvh2, which selectively dephosphorylates the mitogen-activated protein-kinase. J Biol Chem 1995; 13: 7197-203.

183 Franklin CC, Kraft AS. Conditional expression of the mitogenactivated protein kinase (MAPK) phosphatase MKP-1 preferentially inhibits p38 MAPK and stress-activated protein kinase in U937 cells. J Biol Chem 1997; 27: 16917-23.

184 Chi HB, Barry SP, Roth RJ, Wu JJ, Jones EA, Bennettt AM, et al. Dynamic regulation of pro- and anti-inflammatory cytokines by MAPK phosphatase 1 (MKP-1) in innate immune responses. Proc Natl Acad Sci U S A 2006; 7: 2274-9.

185 Kondoh K, Nishida E. Regulation of MAP kinases by MAP kinase phosphatases. Biochim Biophys Acta-Mol Cell Res 2007; 8: 1227 - 
37.

186 Dorfman K, Carrasco D, Gruda M, Ryan C, Lira SA, Bravo R. Disruption of the erp/mkp-1 gene does not affect mouse development: normal MAP kinase activity in ERP/MKP-1-deficient fibroblasts. Oncogene 1996; 5: 925-31.

187 Keyse SM. Dual-specificity MAP kinase phosphatases (MKPs) and cancer. Cancer Metastasis Rev 2008; 2: 253-61.

188 Lawan A, Shi H, Gatzke F, Bennett AM. Diversity and specificity of the mitogen-activated protein kinase phosphatase-1 functions. Cell Mol Life Sci 2013; 2: 223-37.

189 Loda M, Capodieci P, Mishra R, Yao H, Corless C, Grigioni W, et al. Expression of mitogen-activated protein kinase phosphatase-1 in the early phases of human epithelial carcinogenesis. Am J Pathol 1996; 5: 1553-64.

190 Magi-Galluzzi C, Mishra R, Fiorentino M, Montironi R, Yao H, Capodieci $\mathrm{P}$, et al. Mitogen-activated protein kinase phosphatase 1 is overexpressed in prostate cancers and is inversely related to apoptosis. Lab Invest 1997; 1: 37-51.

191 Zhang L, Zhou W, Velculescu VE, Kern SE, Hruban RH, Hamilton SR, et al. Gene expression profiles in normal and cancer cells. Science 1997; 5316: 1268-72.

192 Magi-Galluzzi C, Montironi R, Cangi MG, Wishnow K, Loda M. Mitogen-activated protein kinases and apoptosis in PIN. Virchows Arch Int J Pathol 1998; 5: 407-13.

193 Denkert C, Schmitt WD, Berger S, Reles A, Pest S, Siegert A, et al. Expression of mitogen-activated protein kinase phosphatase-1 (MKP-1) in primary human ovarian carcinoma. Int J Cancer 2002; 5: 507-13.

194 Vicent S, Garayoa M, Lopez-Picazo JM, Lozano MD, Toledo G, Thunnissen F, et al. Mitogen-activated protein kinase phosphatase-1 is overexpressed in non-small cell lung cancer and is an independent predictor of outcome in patients. Clin Cancer Res 2004; 11: 363949.

195 Srikanth S, Franklin CC, Duke RC, Kraft AS. Human DU145 prostate cancer cells overexpressing mitogen-activated protein kinase phosphatase-1 are resistant to Fas ligand-induced mitochondrial perturbations and cellular apoptosis. Mol Cell Biochem 1999; 1-2: 169-78.

196 Small GW, Shi YY, Higgins LS, Orlowski RZ. Mitogen-activated protein kinase phosphatase-1 is a mediator of breast cancer chemoresistance. Cancer Res 2007; 9: 4459-66.

197 Small GW, Shi YY, Edmund NA, Somasundaram S, Moore DT, Orlowski RZ. Evidence that mitogen-activated protein kinase phosphatase-1 induction by proteasome inhibitors plays an antiapoptotic role. Mol Pharmacol 2004; 6: 1478-90.

198 Rojo F, Gonzalez-Navarrete I, Bragado R, Dalmases A, Menendez $\mathrm{S}$, Cortes-Sempere $\mathrm{M}$, et al. Mitogen-activated protein kinase phosphatase-1 in human breast cancer independently predicts prognosis and is repressed by doxorubicin. Clin Cancer Res 2009; 10: 3530-9.

199 Chattopadhyay S, Machado-Pinilla R, Manguan-Garcia C, BeldaIniesta C, Moratilla C, Cejas P, et al. MKP1/CL100 controls tumor growth and sensitivity to cisplatin in non-small-cell lung cancer. Oncogene 2006; 23: 3335-45.

200 Valjent E, Caboche J, Vanhoutte P. Mitogen-activated protein kinase/ extracellular signal-regulated kinase induced gene regulation in brain - A molecular substrate for learning and memory? Mol Neurobiol 2001; 2-3: 83-99.

201 Kristiansen M, Hughes R, Patel P, Jacques TS, Clark AR, Ham J. Mkp1 is a c-jun target gene that antagonizes jnk-dependent apoptosis in sympathetic neurons. J Neurosci 2010; 32: 10820-32.
202 Jeanneteau F, Deinhardt K. Fine-tuning MAPK signaling in the brain: The role of MKP-1. Commun Integr Biol 2011; 3: 281-3.

203 Jeanneteau F, Deinhardt K, Miyoshi G, Bennett AM, Chao MV. The MAP kinase phosphatase MKP-1 regulates BDNF-induced axon branching. Nat Neurosci 2010; 11: 1373-79.

204 Duric V, Banasr M, Licznerski P, Schmidt HD, Stockmeier CA, Simen $\mathrm{AA}$, et al. A negative regulator of MAP kinase causes depressive behavior. Nat Med 2010; 11: 1328-32.

205 Stephens BJ, Han HY, Gokhale V, Von Hoff DD. PRL phosphatases as potential molecular targets in cancer. Mol Cancer Ther 2005; 11 : 1653-61.

206 Zeng Q, Si XN, Horstmann H, Xu Y, Hong WJ, Pallen CJ. Prenylationdependent association of protein-tyrosine phosphatases PRL-1, -2, and -3 with the plasma membrane and the early endosome. J Biol Chem 2000; 28: 21444-52.

207 Sun JP, Wang WQ, Yang H, Liu SJ, Liang F, Fedorov AA, et al. Structure and biochemical properties of PRL-1, a phosphatase implicated in cell growth, differentiation, and tumor invasion. Biochemistry 2005; 36: 12009-21.

208 Achiwa H, Lazo JS. PRL-1 tyrosine phosphatase regulates c-Src levels, adherence, and invasion in human lung cancer cells. Cancer Res 2007; 2: 643-50.

209 Liang FB, Liang J, Wang WQ, Sun AP, Udho E, Zhang ZY. PRL3 promotes cell invasion and proliferation by down-regulation of Csk leading to Src activation. J Biol Chem 2007; 8: 5413-9.

210 Wang Y, Lazo JS. Metastasis-associated phosphatase PRL-2 regulates tumor cell migration and invasion. Oncogene 2012; 7: 818-27.

211 Min SH, Kim DM, Heo YS, Kim YI, Kim HM, Kim J, et al. New p53 target, phosphatase of regenerating liver 1 (PRL-1) downregulates p53. Oncogene 2009; 4: 545-54.

212 Min SH, Kim DM, Heo YS, Kim HM, Kim IC, Yoo OJ. Downregulation of p53 by phosphatase of regenerating liver 3 is mediated by MDM2 and PIRH2. Life Sci 2010; 1-2: 66-72.

213 Luo Y, Liang FB, Zhang ZY. PRL1 promotes cell migration and invasion by increasing MMP2 and MMP9 expression through Src and ERK1/2 pathways. Biochemistry 2009; 8: 1838-46.

214 Peng L, Xing X, Li W, Qu L, Meng L, Lian S, et al. PRL-3 promotes the motility, invasion, and metastasis of LoVo colon cancer cells through PRL-3-integrin beta1-ERK1/2 and-MMP2 signaling. Mol Cancer 2009; 8: 110.

215 Bessette DC, Qiu DX, Pallen CJ. PRL PTPs: mediators and markers of cancer progression. Cancer Metastasis Rev 2008; 2: 231-52.

216 Campbell AM, Zhang ZY. Phosphatase of regenerating liver: a novel target for cancer therapy. Expert Opin Ther Targets 2014; 5: 55569.

217 Stephens B, Han HY, Hostetter G, Demeure MJ, Von Hoff DD. Small interfering RNA-mediated knockdown of PRL phosphatases results in altered Akt phosphorylation and reduced clonogenicity of pancreatic cancer cells. Mol Cancer Ther 2008; 1: 202-10.

218 Nakashima M, Lazo JS. Phosphatase of regenerating liver-1 promotes cell migration and invasion and regulates filamentous actin dynamics. J Pharmacol Exp Ther 2010; 2: 627-33.

219 Yagi T, Morimoto A, Eguchi M, Hibi S, Sako M, Ishii E, et al. Identification of a gene expression signature associated with pediatric AML prognosis. Blood 2003; 5: 1849-56.

220 Hardy S, Wong NN, Muller WJ, Park M, Tremblay ML. Overexpression of the protein tyrosine phosphatase PRL-2 correlates with breast tumor formation and progression. Cancer Res 2010; 21: 8959-67.

221 Rios P, Li X, Kohn M. Molecular mechanisms of the PRL phosphatases. FEBS J 2013; 2: 505-24. 
222 Peng LR, Ning JY, Meng L, Shou CC. The association of the expression level of protein tyrosine phosphatase PRL-3 protein with liver metastasis and prognosis of patients with colorectal cancer. J Cancer Res Clin Oncol 2004; 9: 521-6.

223 Zeng Q, Dong JM, Guo K, Li J, Tan HX, Koh V, et al. PRL-3 and PRL-1 promote cell migration, invasion, and metastasis. Cancer Res 2003; 11: $2716-22$.

224 Kato H, Semba S, Miskad UA, Seo Y, Kasuga M, Yokozaki H. High expression of PRL-3 promotes cancer cell motility and liver metastasis in human colorectal cancer: a predictive molecular marker of metachronous liver and lung metastases. Clin Cancer Res 2004; 21: 7318-28.

225 Rouleau C, Roy A, St Martin T, Dufault MR, Boutin P, Liu DP, et al. Protein tyrosine phosphatase PRL-3 in malignant cells and endothelial cells: expression and function. Mol Cancer Ther 2006; 2: 219-29.

226 Walls CD, lliuk A, Bai YP, Wang M, Tao WA, Zhang ZY. Phosphatase of regenerating liver 3 (PRL3) provokes a tyrosine phosphoproteome to drive prometastatic signal transduction. Mol Cell Proteomics 2013; 12: 3759-77.

227 Al-aidaroos AQO, Yuen HF, Guo K, Zhang SD, Chung TH, Chng WJ, et al. Metastasis-associated PRL-3 induces EGFR activation and addiction in cancer cells. J Clin Invest 2013; 8: 3459-71.

228 Dong YS, Zhang $\sqcup$, Zhang S, Bai YP, Chen HY, Sun XX, et al. Phosphatase of regenerating liver 2 (PRL2) is essential for placental development by down-regulating PTEN (phosphatase and tensin homologue deleted on chromosome 10) and activating AKT protein. J Biol Chem 2012; 38: 32172-79.

229 Dong YS, Zhang L, Bai YP, Zhou HM, Campbell AM, Chen HY, et al. Phosphatase of regenerating liver 2 (PRL2) deficiency impairs kit signaling and spermatogenesis. J Biol Chem 2014; 6: 3799-810.

230 Kobayashi M, Bai Y, Dong Y, Yu H, Chen S, Gao R, et al. PRL2/ PTP4A2 phosphatase is important for hematopoietic stem cell selfrenewal. Stem Cells 2014; 32: 1956-67.

231 Ramponi G, Stefani M. Structural, catalytic, and functional properties of low M-r phosphotyrosine protein phosphatases. Evidence of a long evolutionary history. Int J Biochem Cell Biol 1997; 2: 279-92.

232 Dissing J, Johnsen AH, Sensabaugh GF. Human red-cell acidphosphatase (ACP1) - the amino-acid-sequence of the 2 isozymes BF and BS encoded by the acp1-star-b allele. J Biol Chem 1991; 31: 20619-25.

233 Wo YYP, McCormack AL, Shabanowitz J, Hunt DF, Davis JP, Mitchell GL, et al. Sequencing, cloning, and expression of human red celltype acid-phosphatase, a cytoplasmic phosphotyrosyl protein phosphatase. J Biol Chem 1992; 15: 10856-65.

234 Zhang M, Stauffacher CV, Lin DY, Van Etten RL. Crystal structure of a human low molecular weight phosphotyrosyl phosphatase Implications for substrate specificity. J Biol Chem 1998; 34: 2171420.

235 Chiarugi P, Cirri P, Raugei G, Camici G, Dolfi F, Berti A, et al. PDGF receptor as a specific in vivo target for low $\mathrm{m}(\mathrm{r})$ phosphotyrosine protein phosphatase. FEBS Lett 1995; 1: 49-53.

236 Chiarugi P, Cirri P, Raugei G, Manao G, Taddei L, Ramponi G. Low $\mathrm{M}(\mathrm{r})$ phosphotyrosine protein phosphatase interacts with the PDGF receptor directly via its catalytic site. Biochem Biophys Res Commun 1996; 1: 21-5.

237 Chiarugi P, Cirri P, Taddei ML, Giannoni E, Fiaschi T, Buricchi F, et al. Insight into the role of low molecular weight phosphotyrosine phosphatase (LAM-PTP) on platelet-derived growth factor receptor (PDGF-r) signaling - LMW-PTP controls PDGF-r kinase activity through TYR857 dephosphorylation. J Biol Chem 2002; 40: 37331-8.
238 Chiarugi P, Cirri P, Marra F, Raugei G, Fiaschi T, Camici G, et al. The Src and signal transducers and activators of transcription pathways as specific targets for low molecular weight phosphotyrosine-protein phosphatase in platelet-derived growth factor signaling. J Biol Chem 1998; 12: 6776-85.

239 Zambuzzi WF, Granjeiro JM, Parikh K, Yuvaraj S, Peppelenbosch MP, Ferreira CV. Modulation of Src activity by Low molecular weight protein tyrosine phosphatase during osteoblast differentiation. Cell Physiol Biochem 2008; 5-6: 497-506.

240 Rigacci S, Guidotti V, Parri M, Berti A. Modulation of STAT5 interaction with LMW-PTP during early megakaryocyte differentiation. Biochemistry 2008; 6: 1482-9.

241 Rigacci S, Rovida E, Dello Sbarba P, Berti A. Low Mr phosphotyrosine protein phosphatase associates and dephosphorylates $\mathrm{p} 125$ focal adhesion kinase, interfering with cell motility and spreading. J Biol Chem 2002; 44: 41631-6.

242 Chiarugi P, Cirri P, Taddei L, Giannoni E, Camici G, Manao G, et al. The low $M(r)$ protein-tyrosine phosphatase is involved in Rhomediated cytoskeleton rearrangement after integrin and plateletderived growth factor stimulation. J Biol Chem 2000; 7: 4640-6.

243 Kikawa KD, Vidale DR, Van Etten RL, Kinch MS. Regulation of the EphA2 kinase by the low molecular weight tyrosine phosphatase induces transformation. J Biol Chem 2002; 42: 39274-9.

244 Chiarugi P, Taddei ML, Schiavone N, Papucci L, Giannoni E, Fiaschi T, et al. LMW-PTP is a positive regulator of tumor onset and growth. Oncogene 2004; 22: 3905-14.

245 Parri M, Buricchi F, Taddei ML, Giannoni E, Raugei G, Ramponi G, et al. EphrinA1 repulsive response is regulated by an EphA2 tyrosine phosphatase. J Biol Chem 2005; 40: 34008-18.

246 Zantek ND, Azimi M, Fedor-Chaiken M, Wang BC, Brackenbury R, Kinch MS. E-cadherin regulates the function of the EphA2 receptor tyrosine kinase. Cell Growth Differ 1999; 9: 629-38.

247 Zelinski DP, Zantek ND, Stewart JC, Irizarry AR, Kinch MS. EphA2 overexpression causes tumorigenesis of mammary epithelial cells. Cancer Res 2001; 5: 2301-6.

248 Chiarugi P, Cirri P, Marra F, Raugei G, Camici G, Manao G, et al. LMWPTP is a negative regulator of insulin-mediated mitotic and metabolic signalling. Biochem Biophys Res Commun 1997; 2: 676-82.

249 Pandey SK, Yu XX, Watts LM, Michael MD, Sloop KW, Rivard AR, et al. Reduction of low molecular weight protein-tyrosine phosphatase expression improves hyperglycemia and insulin sensitivity in obese mice. J Biol Chem 2007; 19: 14291-9.

250 Bottini N, MacMurray J, Peters W, Rostamkhani M, Comings DE. Association of the acid phosphatase (ACP1) gene with triglyceride levels in obese women. Mol Genet Metab 2002; 3: 226-9.

251 Bottini N, Bottini E, Gloria-Bottini F, Mustelin T. Low-molecular-weight protein tyrosine phosphatase and human disease: in search of biochemical mechanisms. Arch Immunol Ther Exp (Warsz) 2002; 2: 95-104.

252 Sadhu K, Reed SI, Richardson H, Russell P. Human homolog of fission yeast CDC25 mitotic inducer is predominantly expressed in G2. Proc Natl Acad Sci U S A 1990; 13: 5139-43.

253 Galaktionov K, Beach D. Specific activation of CDC25 tyrosine phosphatases by B-type cyclins - evidence for multiple roles of mitotic cyclins. Cell 1991; 6: 1181-94.

254 Nagata A, Igarashi M, Jinno S, Suto K, Okayama H. An additional homolog of the fission yeast $\mathrm{CDC} 25^{+}$gene occurs in humans and is highly expressed in some cancer-cells. New Biol 1991; 10: 959-68.

255 Lyon MA, Ducruet AP, Wipf P, Lazo JS. Dual-specificity phosphatases as targets for antineoplastic agents. Nat Rev Drug Discov 2002; 12 : 961-76. 
256 Kristjansdottir K, Rudolph J. Cdc25 phosphatases and cancer. Chem Biol 2004; 8: 1043-51.

257 Karisson-Rosenthal C, Millar JBA. Cdc25: mechanisms of checkpoint inhibition and recovery. Trends Cell Biol 2006; 6: 285-92.

258 Hoffmann I, Draetta G, Karsenti E. Activation of the phosphataseactivity of human CDC25A by a CDK2 cyclin-E dependent phosphorylation at the G(1)/S transition. EMBO J 1994; 18: 4302-10.

259 Jinno S, Suto K, Nagata A, Igarashi M, Kanaoka Y, Nojima H, et al. CDC25A is a novel phosphatase functioning early in the cell-cycle. EMBO J 1994; 7: 1549-56.

260 Blomberg I, Hoffmann I. Ectopic expression of Cdc25A accelerates the $\mathrm{G}(1) / \mathrm{S}$ transition and leads to premature activation of cyclin $\mathrm{E}$ and cyclin A-dependent kinases. Mol Cell Biol 1999; 9: 6183-94.

261 Gabrielli BG, DeSouza CPC, Tonks ID, Clark JM, Hayward NK, Ellem $\mathrm{KAO}$. Cytoplasmic accumulation of cdc25B phosphatase in mitosis triggers centrosomal microtubule nucleation in HeLa cells. J Cell Sci 1996; 109: 1081-93.

262 De Souza CPC, Ellem KAO, Gabrielli BG. Centrosomal and cytoplasmic cdc2/cyclin B1 activation precedes nuclear mitotic events. Exp Cell Res 2000; 1: 11-21.

263 Lindqvist A, Kallstrom H, Lundgren A, Barsoum E, Rosenthal CK. Cdc25B cooperates with Cdc25A to induce mitosis but has a unique role in activating cyclin B1-Cdk1 at the centrosome. J Cell Biol 2005; 1: $35-45$.

264 Boutros R, Lobjois V, Ducommun B. CDC25 phosphatases in cancer cells: key players? Good targets? Nat Rev Cancer 2007; 7: 495507.

265 Galaktionov K, Lee AK, Eckstein J, Draetta G, Meckler J, Loda M, et al. CDC25 phosphatases as potential human oncogenes. Science 1995; 5230: 1575-7.

266 Ma ZQ, Chua SS, DeMayo FJ, Tsai SY. Induction of mammary gland hyperplasia in transgenic mice over-expressing human Cdc25B. Oncogene 1999; 32: 4564-76.
267 Yao Y, Slosberg ED, Wang L, Hibshoosh H, Zhang YJ, Xing WQ, et al. Increased susceptibility to carcinogen-induced mammary tumors in MMTV-Cdc25B transgenic mice. Oncogene 1999; 37: 5159-66.

268 Brezak MC, Quaranta M, Contour-Galcera MO, Lavergne 0, Mondesert $\mathrm{O}$, Auvray $\mathrm{P}$, et al. Inhibition of human tumor cell growth in vivo by an orally bioavailable inhibitor of CDC25 phosphatases. Mol Cancer Ther 2005; 9: 1378-87.

269 He YT, Zeng LF, Yu ZH, He RJ, Liu SJ, Zhang ZY. Bicyclic benzofuran and indole-based salicylic acids as protein tyrosine phosphatase inhibitors. Biorg Med Chem 2012; 6: 1940-6.

270 Wiesmann C, Barr KJ, Kung J, Zhu J, Erlanson DA, Shen W, et al. Allosteric inhibition of protein tyrosine phosphatase 1B. Nat Struct Mol Biol 2004; 8: 730-7.

271 Bolton JL, Trush MA, Penning TM, Dryhurst G, Monks TJ. Role of quinones in toxicology. Chem Res Toxicol 2000; 3: 135-60.

272 Monks TJ, Jones DC. The metabolism and toxicity of quinones, quinonimines, quinone methides, and quinone-thioethers. Curr Drug Metab 2002; 4: 425-38.

273 Barf T, Kaptein A. Irreversible protein kinase inhibitors: balancing the benefits and risks. J Med Chem 2012; 14: 6243-62.

274 Sanderson K. Irreversible kinase inhibitors gain traction. Nat Rev Drug Discov 2013; 9: 649-51.

275 Rondinone CM, Trevillyan JM, Clampit J, Gum RJ, Berg C, Kroeger P, et al. Protein tyrosine phosphatase $1 \mathrm{~B}$ reduction regulates adiposity and expression of genes involved in lipogenesis. Diabetes 2002; 8: 2405-11.

276 Zinker BA, Rondinone CM, Trevillyan JM, Gum RJ, Clampit JE, Waring $J F$, et al. PTP1B antisense oligonucleotide lowers PTP1B protein, normalizes blood glucose, and improves insulin sensitivity in diabetic mice. Proc Natl Acad Sci U S A 2002; 17: 11357-62.

277 He R, Zeng LF, He Y, Zhang S, Zhang ZY. Small molecule tools for functional interrogation of protein tyrosine phosphatases. FEBS J 2013; 280: 731-50. 